\title{
التطبيقات التربوية المعاصرة لمقاصد الشريعة الإسلامية الضرورية.
}

\author{
د. أمل راشد إبراهيم الخليفة \\ قسم أصول التربية- كلية التربية \\ جامعة الإمام محمد بن سعود الإسلامية.

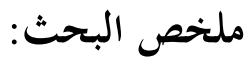

هـدفت الدراسة إلى الكشف عن التطبيقـات التربوية المعاصرة لمقاصد الشريعة الإسـلامية الضرورية

الخمـس وهي:حفظ الـدين والنفس والعقل والنسـب والمـال. ولتحقيـق هـذا الهـدف تم استخدام المـنهج الاسـتباطي. وكـان مـن أبـرز نتـائج الدراسـة: أن دراسـة التطبيقـات التربويـة المعاصـرة لمقاصــ الشـريعة الضرورية هو تأكيد على خلود الشريعة الإسلامية وواقعيتها وصلاحيتها للتطبيق ودورها في إيجاد الحلول للمشكلات والمستجدات التربوية. كذلك فإن من التطبيقات التربوية لمقصد حفظ الدين التربية على العمل بـه والدعوة إليه والدفاع عنه,مع ضرورة محاربة المعتقدات الفاسدة والأفكار المنحرفة وتفعيل دور وسائل الإعلام المختلفة في الحفاظ على الدين, كذلك من التطبيقات تشجيع ثقافة الحوار داخل الأسرة والبحتمع. أن من التطبيقات التربوية لمقصد حفظ النفس التربية على حرمة الاعتداء على النفس, ووضع الحـدود مـع التربيـة على فضـل العفـو عـن القصـاص, وتحـيم الانتحـار وإباحـة المخظورات حفاظـا على لى الأنفس. أن مـن التطبيقات التربوية لمقصد حفظ العقل التربية على أهمية العقل والتأكيد على فرضية طلب العلم مع ضرورة تحرير العقل من إرث التصورات والأفكار الجماهلية مع التربية على ممارسة عبادة التفكر لإنشاء العقلية العلمية التي ترفض اتبـاع الظن والهوى.أن مـن التطبيقـات التربوية لمقصد حفظ النسب والنسل التربية على الترغيب في النكاح وتكثير النسل مع التأكيد على حرمة قتل الأولاد ونفي النسب وكذلك حرمة الزنا واللواط والقذف. أن من التطبيقات التربوية لمقصد حفظ المال التربية على أن المـال مـال الله مـع ضــورة السـعي والكسـب الحـلال وعـدم إضـاعة المـال, وضـــورة أداء الحقـوق لأهلها والتأكيد على حرمة كل صور أكل أموال الناس بالباطل. 
تعـاني العلـوم التربويـة مـن أزمـة, ذلك أهـا تبلـورت ونضـجت على يـــ الغـربيين, وإن حبلهـا عـن المسلمين قد انقطع كما يؤكد العلواني( آ إ اهـ,ص 0م) منذ زمـ بعيد لأسباب متعددة. ولذاكان لابد من ربط تلك العلوم بمصادرها الأساسية وبعلوم الشريعة, حيث أن الفصل بينها من أكبر الأسباب

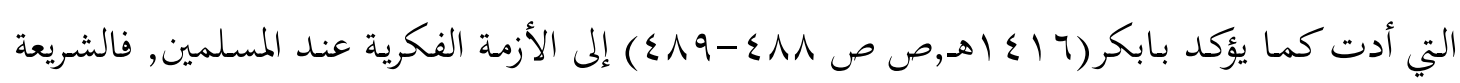
تشمل كل العلوم الاجتماعية والإنسانية فهي محكومة بأحكام شرعية ابتداء من كلياتها وانتهاءً بجزئياما وتفصيلاتما, بل إن غايات تلك العلوم يجب أن تصب في دائرة غايات ومقاصد الشريعة التي تستهدف مصلحة الإنسان. ولعل من المباحث المهمة في الشريعة التي يمكن للتربية أن تستفيد منها في مناهجها وأهدافها وممارساها ما اصطلح عليه علماء الشريعة بتسميته مقاصد الشريعة التي تنقسم إلى أنواع ثلاث وهي: الضروريات والحاجيات والتحسينات, وقد أكد على أهميتها الخادمي(ا إع اهرص V) فهي ضرورة ملحة على صعيد فهم التكليف وتعقله واستيعابه وتطبيقه, وعلى صعيد تحمل خطاب التكاليف, وأداء رسـالة الاسـتخلاف, وإقامـة واجـب الإصـلاح والتوجيسه والإرشـاد في الأرض. بـل إن المقاصـد عنــ

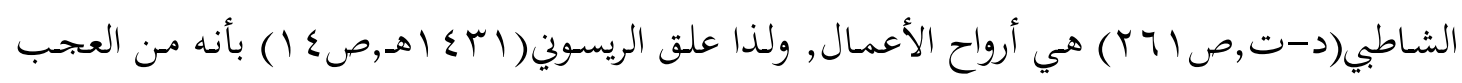
أن يعيش الناس بلا مقاصد أي بلا أرواح.

لقد شرع الإسلام من الأحكام والتكاليف ما يحمي تلك المقاصد والمصالح خاصة التي تبلغ الحاجة إليها مبلغ الضـرورة, ولا تقـوم حيـاة النـاس بـدوها, وهـي المقاصــ التي انتهى إليهـا العلمـاء كمـا يؤكـد الريسوني( آب إهـ,ص بT) مـن حفـظ الـدين والـنفس والعقـل والنسـل والمـال. فهي ضـروريات لازمـة للإنسـان مـن حيث هو إنسـان, كمـا تعد أصولا راسخحة لحقوق الإنسان العامة التي ينادي بها البحتمع الإنسـاني في العصـر الحـديث. أن تلـك المقاصــ الضـرورية تسـتوعب حيـاة الإنسـان كلهـا كمــا يــى

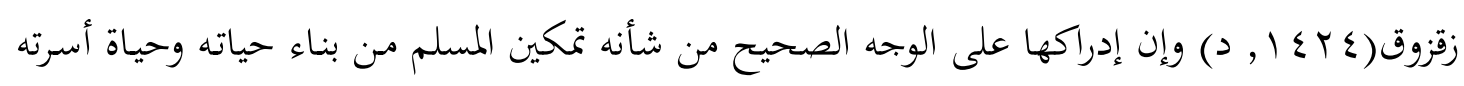
وبحتمعه والإسهام في بناء الحضارة الإنسانية وإرساء دعائم الأمن والسلام في العالم.

\section{مشكلة الدراسة:}

إن دراسة الجانب التربوي في مقاصد الشريعة الإسلامية يسهم في ترسيخ العلاقة الوثيقة بين الشريعة والتربية, فالشريعة الإسلامية تستهدف ما تهدف إليه التربية من إسعاد الأفراد والجماعة وحفظ النظام, 
وتعمير الدنيا بكل ما يوصل إلى الخير والكمال الإنساني, حتى تصير الدنيا مزرعة للآخرة. كذلك فإن دراسة الجوانب التربوية في تلك المقاصد يسهم في تقوية صلة العلوم التربوية والإنسانية عموما بالتراث

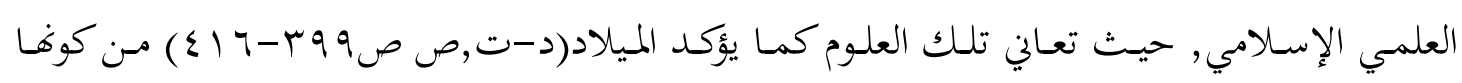
علوم مقطوعة الصلة بالبمتمع العربي, ولذا بقيت عاجزة عن تطويره, كذلك فإن تلك العلوم تعاني من

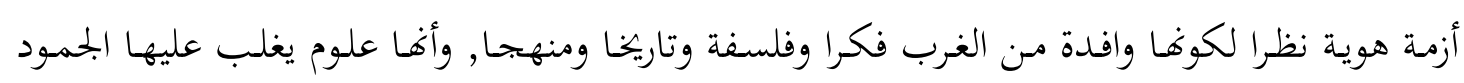

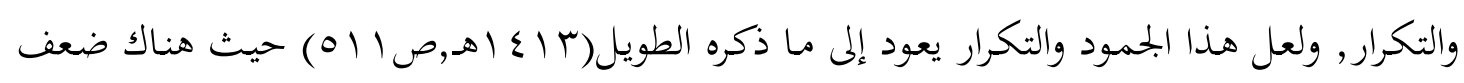
في الإعداد العلمي للباحثين المتخصصين في العلوم الإنسانية من حيث معرفتهم بالعلوم الشرعية. إن دراسة التطبيقات المعاصرة للمقاصد لها أهمية في زيادة مكانة المقاصد في العصر الحالي كما يؤكد

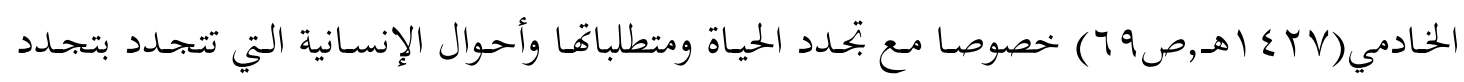

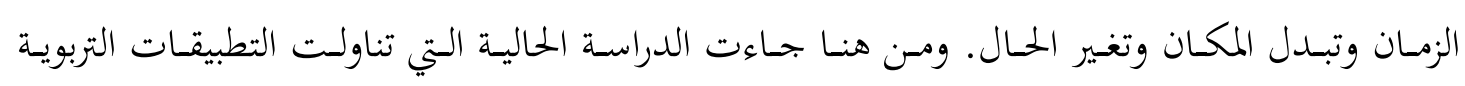

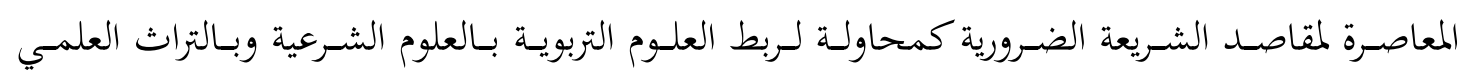

$$
\text { الإسلامي. }
$$

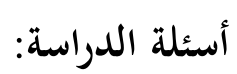

السؤال الرئيس: ما النطبيقات التربوية المعاصرة لمقاصد الشريعة الإسلامية الضرورية؟ ولإجابة عليه

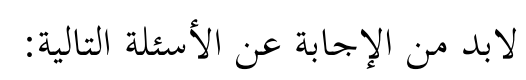

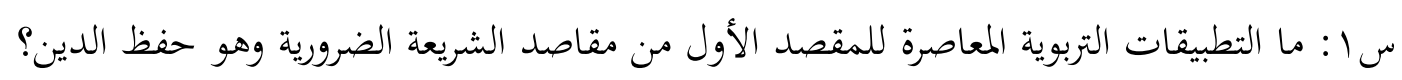

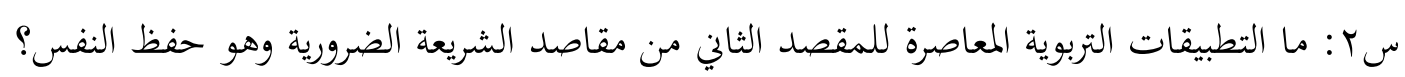

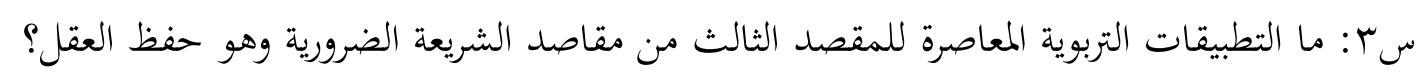

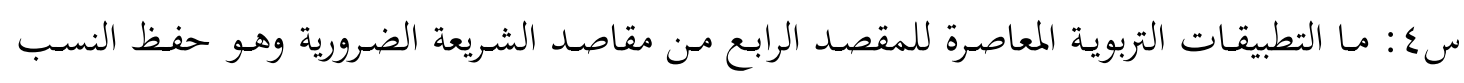
(النسل)

س ه: ما التطبيقات التربوية المعاصرة للمقصد الخامس من مقاصد الشريعة الضرورية وهو حفظ المال؟

\section{أهداف الدراسة:} تحدف الدراسة الحالية إلى التعرف على التطبيقات التربوية المعاصرة لمقاصد الشريعة الضرورية وذلك من

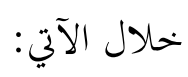
1. معرفة التطبيقات التربوية المعاصرة لمقصد حفظ الدين. 
r. م معرفة التطبيقات التربوية المعاصرة لمقصد حفظ النفس.

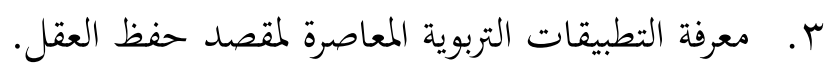

ع . معرفة التطبيقات التربوية المعاصرة لمقصد حفظ النسب(النسل).

ه. معرفة التطبيقات التربوية المعاصرة لمقصد حفظ المال.

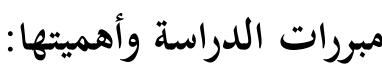

1. تأتي هذه الدراسة تلبية للاهتمام المتزايد بأهمية دراسة مقاصد الشريعة من جميع جوانبها, وتزايد

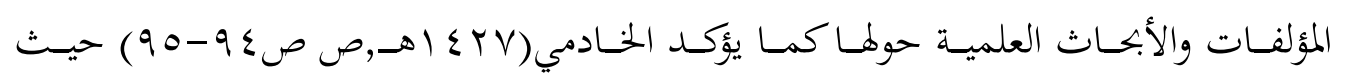
أصبحت المقاصد منهجا يدرس ومقررا معتمدا في بعض الكليات والمعاهد التابعة لجامعة الإمام محمد بن سعود الإسلامية والجامعات الإسلامية, إلى جانب اهتمام البحامع الفقهية والمراكز البحثية والهيئات العلمية كمجمع الفقه الإسلامي الدولي بحدة التابع لمنظمة المؤتمر الإسلامي

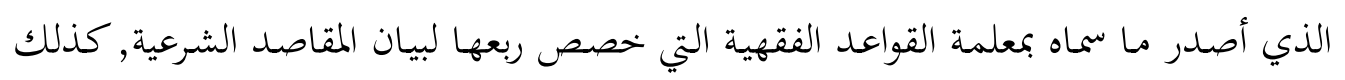
جهود وزارة الأوقاف والشؤون الإسلامية في المملكة العربية السعودية التي أشرفت على الموسوعة الأصولية بحيث كان للمقاصد الشرعية نصيب كبير, كذلك خصص مركز الملك فيصل للبحوث والدراسات الإسلامية بالرياض جائزته العالمية سنة ب بـ اهـ لموضوع مقاصد الشريعة, ونظرا لمذا الاهتمام المتزايد بالمقاصد, كان لابد من الإسهام فيه من الناحية التربوية. r. تحاول الدراسة الحالية من خحلال دراسة التطبيقات التربوية المعاصرة لمقاصد الشريعة الضرورية التأكيد على خلود الشريعة الإسلامية وواقعيتها وصلاحيتها للتطبيق في كل زمان ومكان وحال,

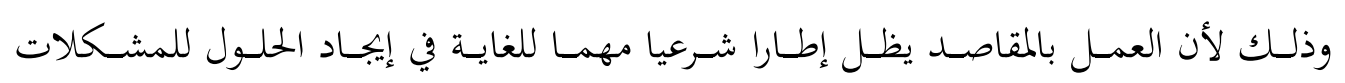
والمستجدات.

r. إن أهمية الدراسة الحالية تأتي من أهمية الجانب التطبيقي لمقاصد الشريعة الضرورية وذلك لمن أراد

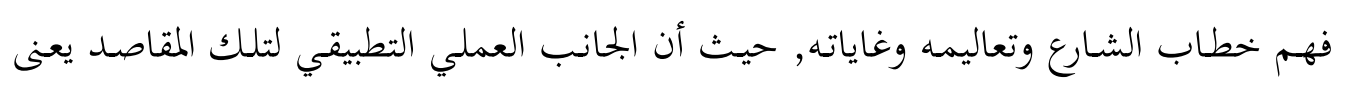
بتنزيل العلم في أرض الواقع ليعالج الحوادث والمشـكلات وليتصـدى بالبيـان والتوجيه للنوازل

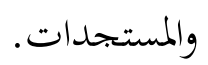


ع. تأتي أهمية الدراسة من أهمية المقاصد الشرعية ذاها, حيث أفها بمثابة البوصلة التي تحدد للمسافر صحة ابتحاهه من عدمه فهي تساعد الباحث عن أحكام الشريعة في تحديد صحة سيره وسلامة طريقه في التعامل مع نصوص الكتاب والسنة وعباراتا واستخراج واستنباط مدلولاتما ومعانيها ومراميها. ه. ـأتي الدراسـة الحاليـة أيضـا استتجابة لحاجـة المحال التربوي للربط بينه وبـين العلوم الإسـلامية وخاصة علم أصول الفقه, ولذا تحاول الباحثة إلقاء الضوء على بعض قضايا علم أصول الفقه من خحلال المقاصد الشرعية, أملا أن يثير هذا الموضوع اهتمام المتخصصين والباحثين في بحال التربية ويدفعهم إلى مزيد من البحث والربط بين العلوم المختلفة بما يحقق التكامل بينها. ج. لقد أوصت عدد من المؤتمرات والندوات المهتمة بمقاصد الشريعة الإسلامية بأهمية دراستها من جميع جوانبها, ولعل الدراسـة الحاليـة تسهم في دعـم الجانـب التربوي لمقاصد الشـيعة, حيـث أوصى المؤتمر العلمي الذي كان بعنوان: مقاصد الشريعة وتطبيقاهـا المعاصرة والمنعقد في الفترة

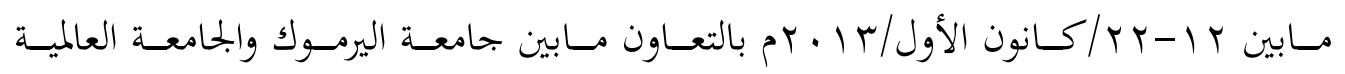
الإسـلامية بالحاجـة الكبـيرة إلى تفعيل الجانـب العملي التطبيقـي لمقاصــ الشـيعة خروجـا مـن الجانب النمطي التجريدي. V. إن المقاصد الضـرورية هي أساس جميع المقاصد كما يؤكد أسعد المحاسن(r I · rم) ولذا فهي المقصـودة بـالحفظ والاعتبـار بالدرجـة الأولى, وبقيـة المصــالح خحادمـة لهـا. أمـا الشـاطبي(دت,صع بr) فيرى بأنه لو اختلدت أو لم تكن موجسودة لأدى ذلك إلى خلل في حياة الناس واضطربت أحوالهم, وعم الفساد وانتشرت الفوضى, فمعناه أنه لابد منها في قيام مصالح الدين والدنيا بحيث إذا فقدت لم تستقيم مصالح الدنيا, وفي الأخرى فوت النجاة.

الحـدود الموضـوعية: اقتصـرت الدراسـة الحاليـة على دراسـة التطبيقـات التربويـة لمقاصـد الشـريعة الضـرورية الخمسة وهي: حفظ النفس, الدين, المال, العقل والنسب, وذلك لأغها الأصل وما عداها تكملة لما, فإذا فقدت اختلت الحياة الإنسانية. 
مقاصد الشريعة الإسلامية الضرورية: ولتعريف بهذا الإسم المركب لابد من تعريف ألفاظه على النحو

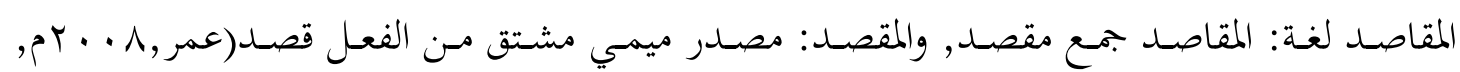

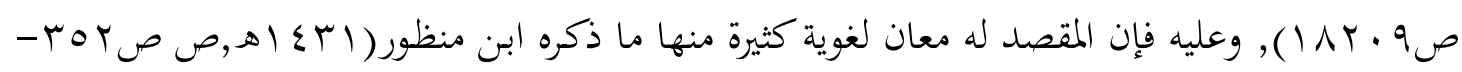

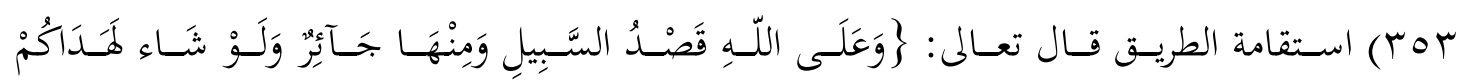
أَمْمَعِن \{ [النحل:9] , وكذلك التوسط وعدم الإفراط والتفريط لقوله صلى الله عليه وسلم:"القَصدَ القصدَ

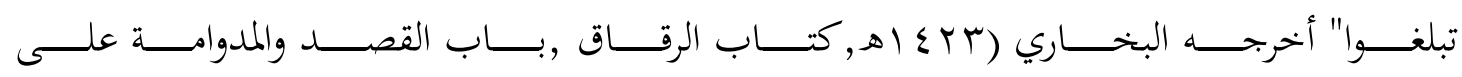

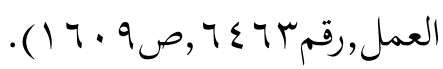

أما الشريعة لغة: فتطلق على مورد الماء ومنبعهه ومصدره كما ذكر ابن منظور( آبـ اهـ,ص ص • ع( ) وتطلق على الدين والملة والطريقة.

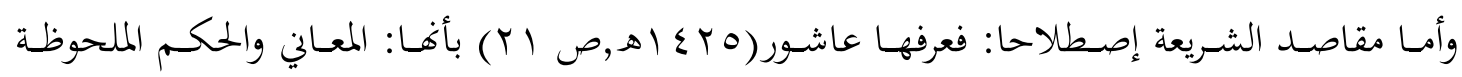
للشارع في جميع أحوال التشريع أو معظمها.

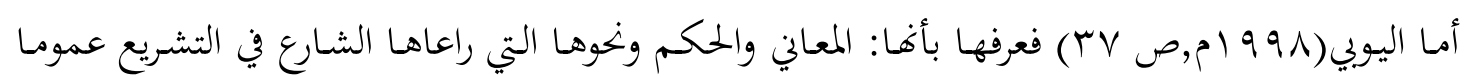
وخصوصا من أجل تحقيق مصالح العباد.

وأما المقاصد الضرورية فقد عرفها الشاطبي(د-ت,صV)بأها: هي التي لابد منها في قيام مصالح الدارين بحيث إذا فقدت لم بحر مصالح الدنيا على استقامة وفي الأخرى فوت النجاة والنعم والرجوع بالخسران وهي حفظ الدين والنفس والعقل والنسل والمال.

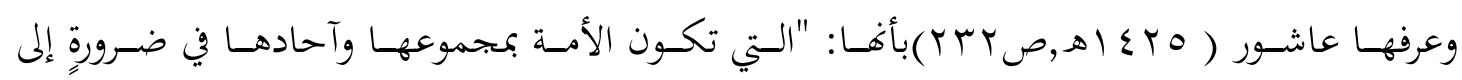
تحصيلها، بحيث لا يستقيم النظام باختلالها، بحيث إذا الخرمت تؤول حالةُ الأمة إلى فسادٍ وتلاثٍٍ". وترى الباحثة أن المقصود بها هي: المصالح التي قصدها الشارع بتشريع الأحكام, والتي لابد منها لإسعاد الخلق في الدنيا والآخرة وهي خمسة مقاصد: الدين والنفس والعقل والنسل والمال. 
أجرى الظبي( • · Y) دراسة بعنوان "التطبيقات التربوية لمقصد حفظ العقل في الإسلام بمحتوى مناهج التربية الإسلامية للمرحلة المتوسطة" هدفت الدراسة إلى تحديد التطبيقات التربوية لمقصد حفظ العقل في الإسـلام اللازمة لطلاب المرحلة المتوسطة بالمملكة العربية السعودية, لمعرفة مـدى تضـمينها في محتوى مناهج التربية الإسلامية. واتبع الباحث منهج تحليل المختوى لتحقيق أهداف الدراسة. وحددت الدراسة

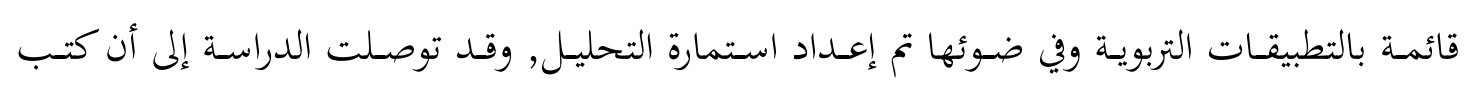
التربية الإسلامية قد تضمنت تلك التطبيقات بدرجة جيدة, وأكدت الدراسة على عدم وجود توازن في

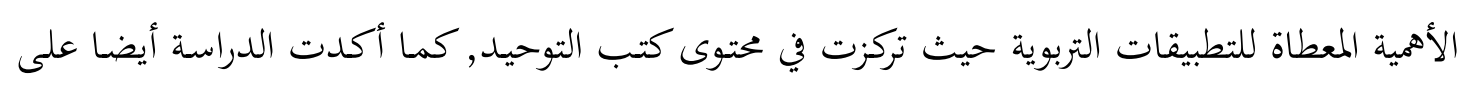

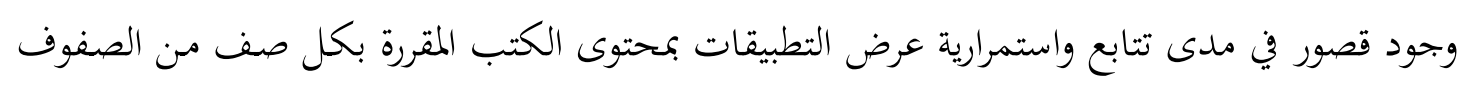
الثلاثة.

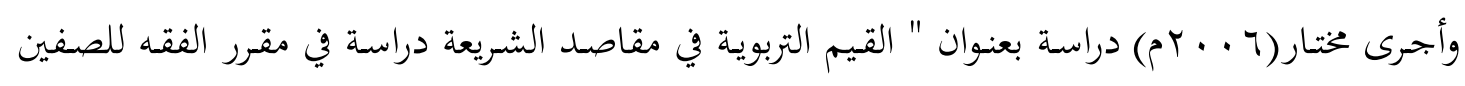

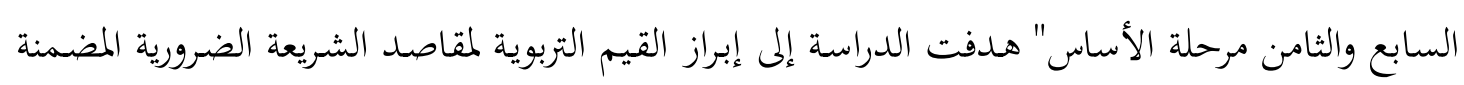
في مقرر الفقه الإسلامي للصفين السابع والثامن في السودان. واتبع الباحث المنهج الوصفي التحليلي,

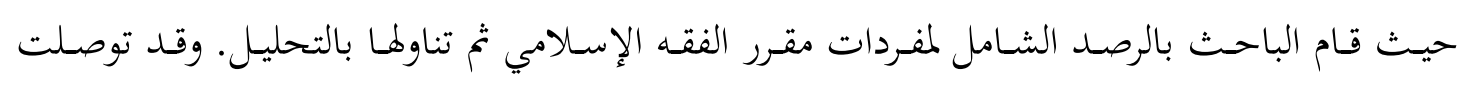

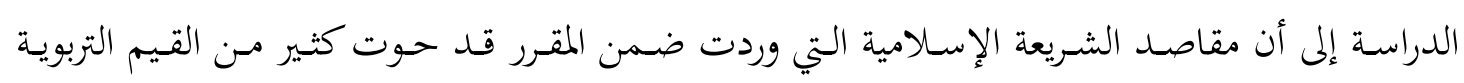
روحية, خلقية, اجتماعية, عقلية وجمالية. وأن للأسرة والمدرسة الدور الأعظم في غرس القيم التربوية بتحاه الأبناء والتلاميذ. كما أشارت الدراسة إلى الأسلوب النبوي في غرس القيم التربوية بطريقة لم يتطرق إليها شرح الكتاب المدرسي كما لم يركز عليها أغلب المدرسين.

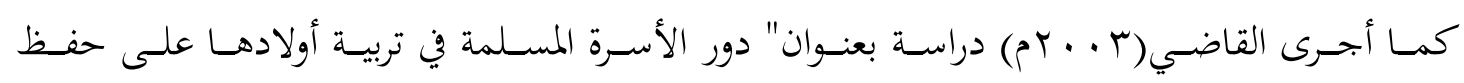
الضروريات من مقاصد الشريعة" وهدفت الدراسة إلى التعرف على دور الأسرة المسلمة في تربية أولادها على حفظ الضروريات من مقاصد الشريعة ولهذا وقفت الدراسة على أهمية حفظ هذه الضروريات في

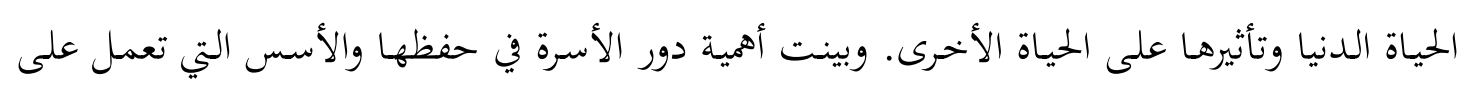

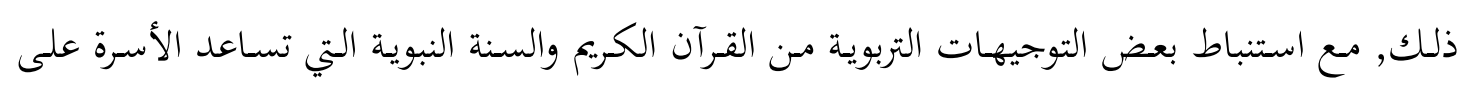
حفظ تلك الضروريات, واستنباط الآثار التربوية المترتبة على حفظ تلك الضروريات. واستخدم الباحث المنهج الاستنباطي لتحقيق أهداف الدراسة. ومن النتائج التي توصلت إليها الدراسة: حاجة الأسرة إلى 
منهج متكامل يكون به سعادتما وفلاحها في الدنيا والآخحة. كما توصلت الدراسة إلى أثر الأسرة في إكساب الأولاد المعارف والمهارات وغير ذلك.

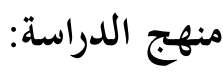

اعتمدت الباحثة في هذه الدراسة على المنهج الاستنباطي من أجل استنباط التطبيقات التربوية لمقاصد

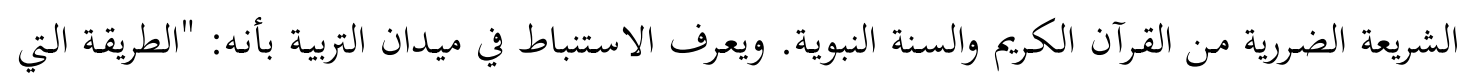
يقوم فيها الباحث ببذل أقصى جهد عقلي ونفسي عند دراسة النصوص، بهدف استخراج مبادئ تربوية

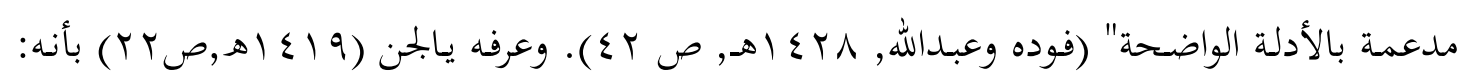

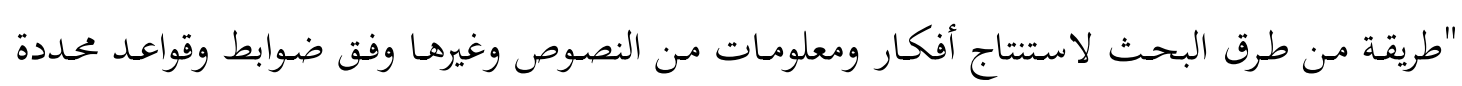
ومتعارف عليها".

إجراءات الدراسة:

قامت هذه الدراسة على عدة خطوات إجرائية من أجل استنباط التطبيقات التربوية من مصادر التشريع

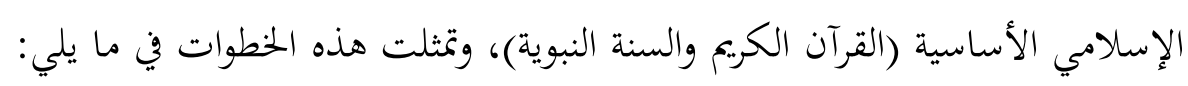

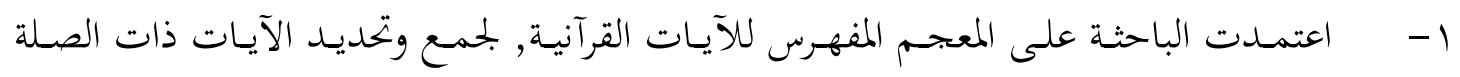
بموضوع الدراسة, حيث حددت الباحثة من خحلال هذه الخطوة جملة من الآيات القرآنية التي تناولت مقاصد الشريعة الضرورية ذات الصلة.

ץ- تدبر آيات القرآن عند القراءة، ومراجعة ما له علاقة بموضوع الدراسة بالاعتماد على التفاسير القرآنية المعتمدة.

r- أيضا اعتمدت الباحثة على المعجم المفهرس لألفاظ الحديث، لجمع وتحديد الأحاديث ذات الصلة بموضوع البحث، كالمعجم المفهرس لألفاظ الحمديث لفنستك، والاعتماد على الكتب الصحاح تحرزا من الوقوع في الأحاديث الضعيفة.

ع - تمخ بعد ذلك اختارت الباحثة بعضا من تلك الآيات والأحاديث وتم تصنيفها وفقا للضروريات الخمسة التي تتعلق .ما. 
ه - فهم وتحليل دلالات هذه النصوص، وذلك يتطلب تفسير هذه النصوص، وقد ركزت الباحثة على كتب التفسير المعتمدة لفهم مراد الله -تعالى - من كل آية، وكتب الحـديث الصحيحة, كذلك الرجوع لاجتهادات العلماء الذين كتبوا حول مقاصد الشريعة الإسلامية, ومن خلال الخطوات السابقة أجابت الباحثة على أسئلة الدراسة حول التطبيقات التربوية التي تفيد المؤسسات التربوية.

أمـاعـن فصـول الدراسـة: فقـد قسمت إلى خمسة مباحـث إضـافة إلى المقدمـة والنتـائج. أمـا المقدمـة فقـد اشتملت على مشكلة الدراسة وأسئلتها وأهدافها ومبررات الدراسة وأهميتها ثم حدودها ومصطلحاها مع عرض للدراسات السابقة وخطة الدراسة. وأما مباحث الدراسة الخمسة فكانت على النحو الآتي: المبحث الأول: التطبيقات التربوية المعاصرة للمقصد الأول من مقاصد الشريعة وهو حفظ الدين. المبحث الثاني: التطبيقات التربوية المعاصرة للمقصد الثاني من مقاصد الشريعة وهو حفظ النفس. المبحث الثالث: التطبيقات التربوية المعاصرة للمقصد الثالث من مقاصد الشريعة وهو حفظ العقل. المبحث الرابع: التطبيقات التربوية المعاصرة للمقصد الرابع من مقاصد الشريعة وهو حفظ النسب. المبحث الخامس: التطبيقات التربوية المعاصرة للمقصد الخامس من مقاصد الشريعة وهو حفظ المال. مباحث الدراسة: المبحـث الأول: النطبيقـات التربويـة المعاصـرة للمقصـد الأول مـن مقاصـد الشـريعة وهـو حفظ الدين: (n)

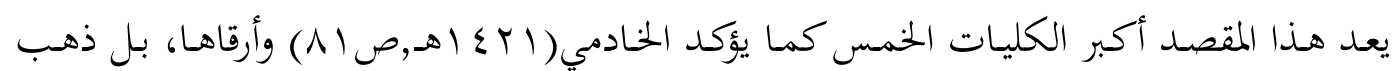
دراز(في الشـاطبي, د-ت,صV) إلى أنه يعـد مقصدا لجميع التكاليف أصسولها وفروعها، وبحفظ الـدين تحفظ بقية الضرورات تبعا لحفظه كما يؤكد الأهدل(· ( إ (هـ، V) لأنه يقتضي حفظها, فإذا ذهـب

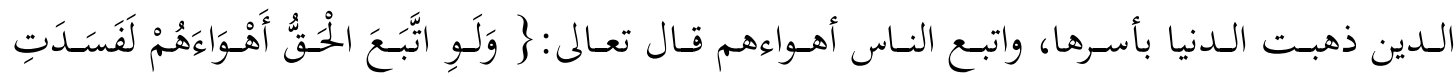

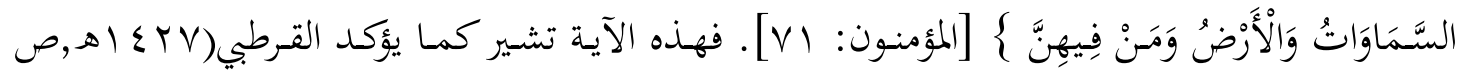
(VT فإذا لم يكن هناك دين يضبط المصالح، وينظم الحياة، فإن كل شخص سيفعل ما يراه مصلحة له بحسب ما يمليه عليه هواه، فيحصل الاعتداء على الأموال، والأنفس، والأعراض، والأنساب. 


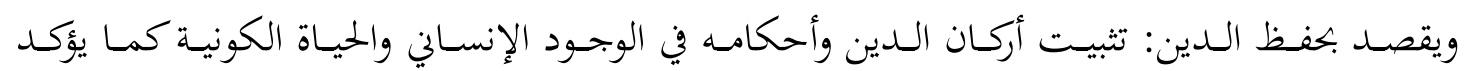

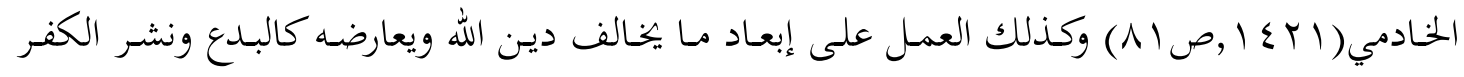
والرذيلة والإلحاد والتهاون في أداء واجبات التكليف. وكأ العمل علئ إبعاد

أما عن التطبيقات التربوية لمقصد حفظ الدين فيمكن إجمالها على النحو الآتي: 1- التربية على العمل بالدين الإسلامي والحكم به في كل شؤون الحياة:

من المعلوم أن هذا الدين ما شرعه الله إلا ليعمل به، حيث لا يمكن أن تستغني روح الإنسان عن

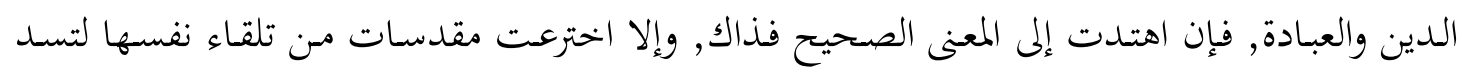

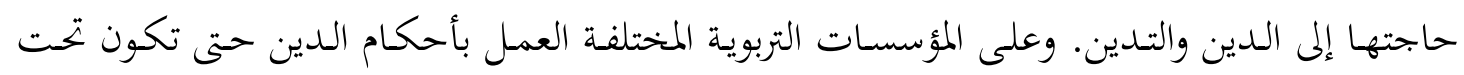

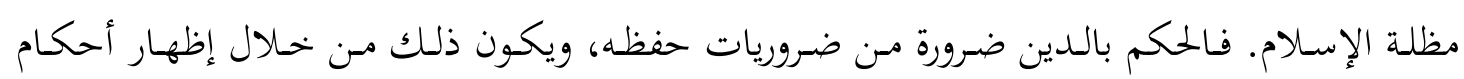

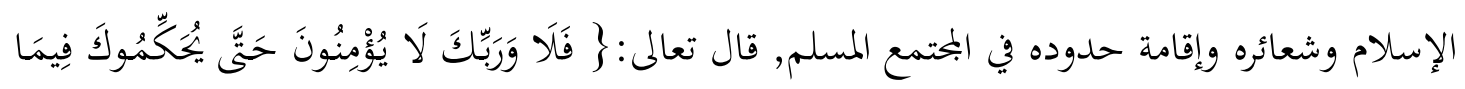

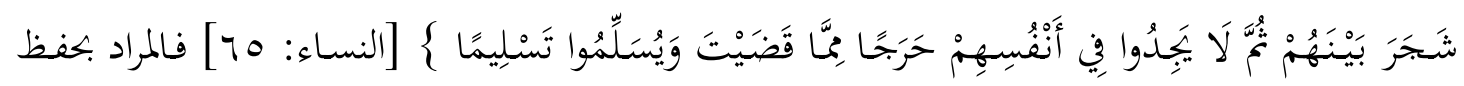

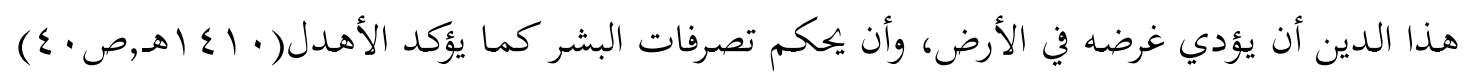

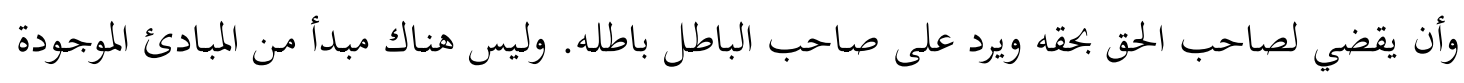

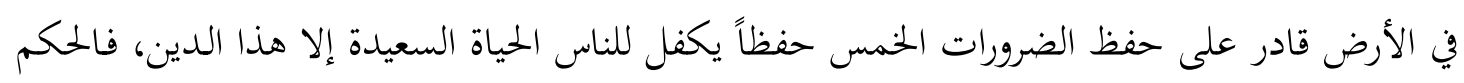
بما أنزل الله ضرورة من ضروريات حفظ الدين.

كذلك فإن الحكم بالدين وتطبيق أحكامه يسد الباب على أهل الأهواء المنحرفة والمذاهب الهدامة

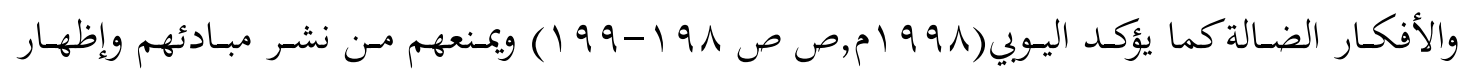

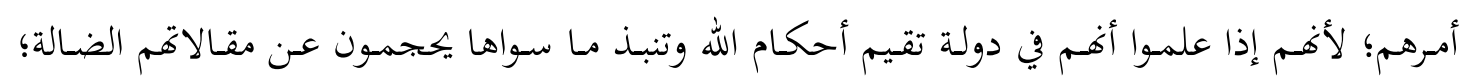

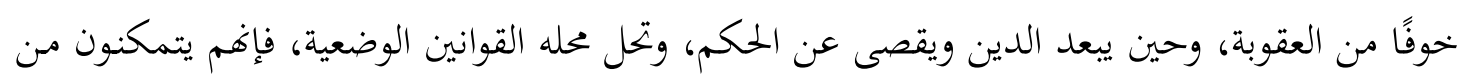

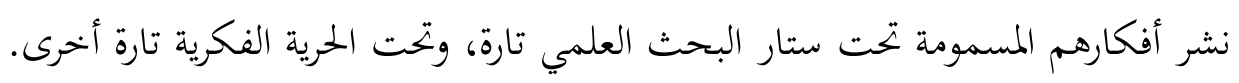

r- التربية على الدعوة إلى الدين حفظا له:

لقد اقتضت حكمة الله عز وجـل أن يكلف أفراد هذه الأمة بمـا كلف به الرسل عليهم الصلاة

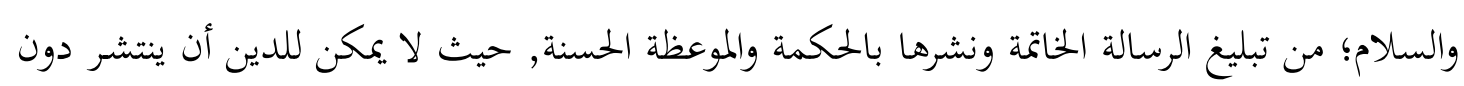

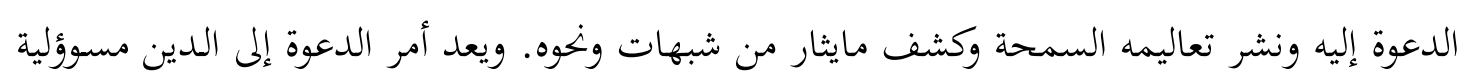

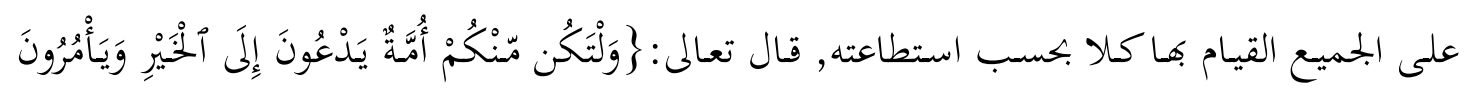




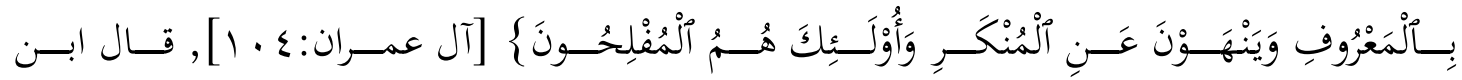

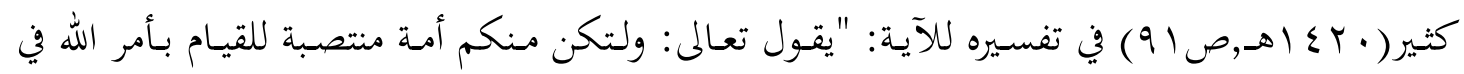
الدعوة إلى الحخير والأمر بالمعروف والنهي عن المنكر وأولئك هم المفلحون". r- التربية على الجهاد في سبيل الله: أن الجهاد هو ذروة سنام العمل الهادف إلى حماية الدين واستمراريته في حياة الناس, قال تعالى:

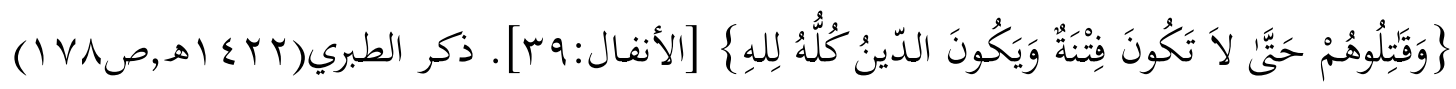

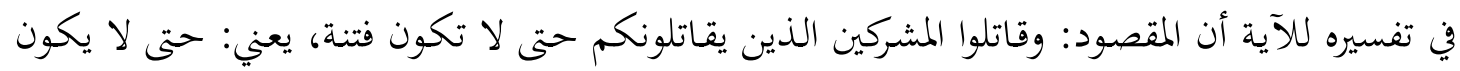

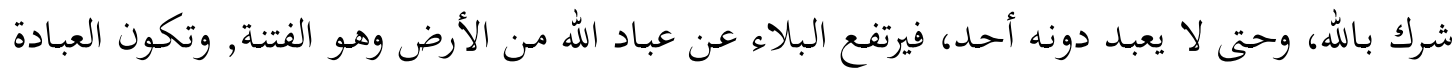
والطاعة لله وحده دون غيره من الأصنام والأوثان.

ع - التربية على محاربة المعتقدات الفاسدة، والأفكار المنحرفة، والمذاهب الهدّامة حتى لا تتسرب إلى

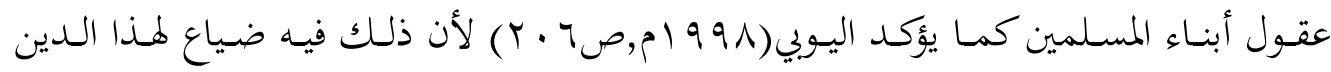

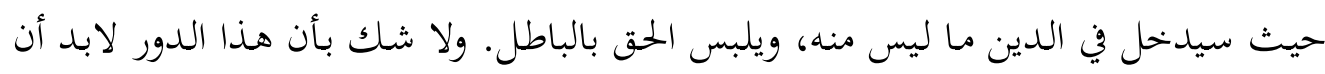

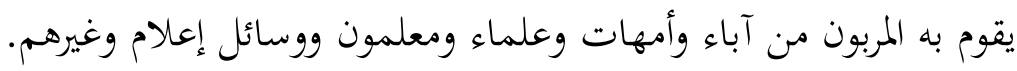

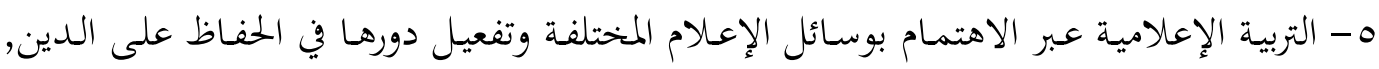

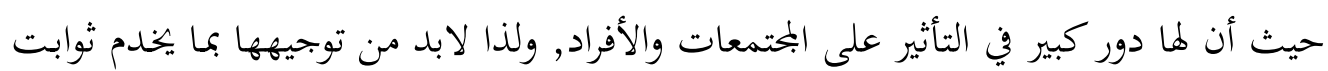

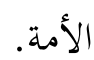
7- تشجيع ثقافة الحوار داخل الأسرة والمجتمع وفي جميع المؤسسات التربوية, وتنمية قيمة قبول الرأي الآخر حتى لا تظهر مظاهر التعصب والغلو والارهاب والردة عن الدين.

المبحـث الثـاني: الثطبيقـات الثربويـة المعاصـرة للمقصـد الثـاني مـن مقاصـد الثـريعة وهو حفظ النفس: حفظ النفس هو الكلية المقاصدية الشرعية الثانية ومعناها عند الخادمي( آ أهـصص (م) مراعاة

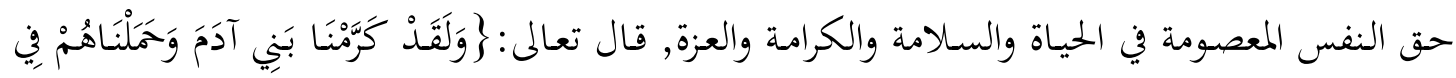

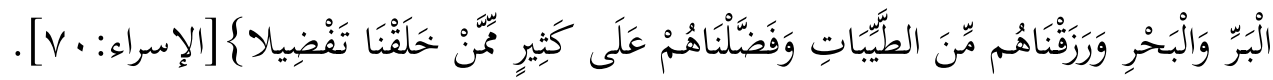
أما عن التطبيقات التربوية لمقصد حفظ النفس فيمكن إجمالها على النحو الآتي: اـ التربية على حرمة الاعتداء على النفس: 


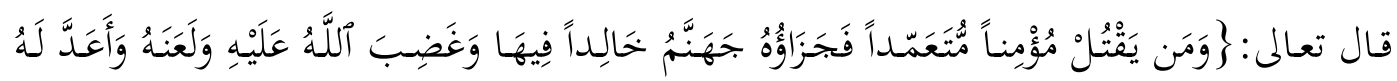

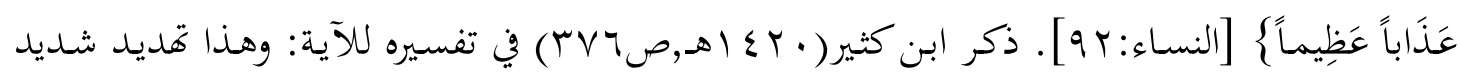

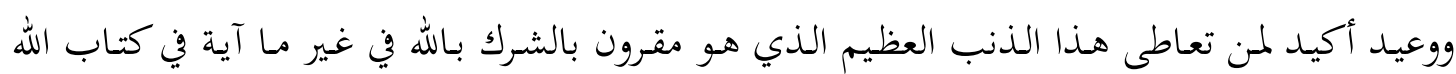

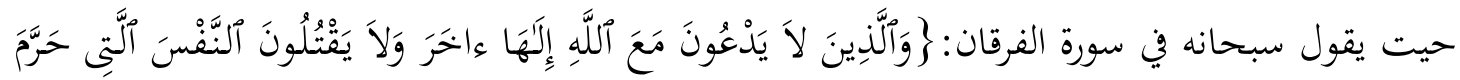

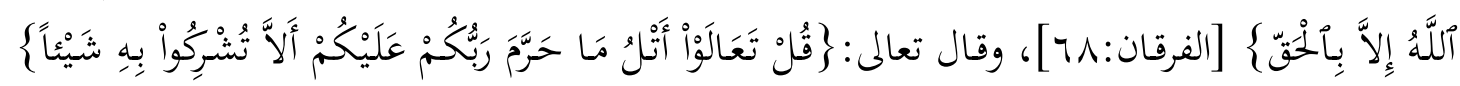

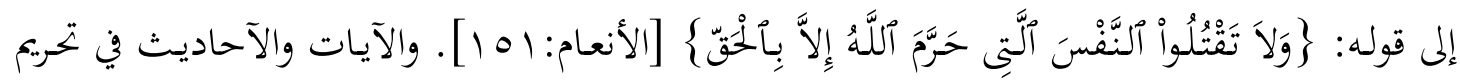

$$
\text { القتل كثيرة جداً. }
$$

$$
\text { r. التربية على منع كل ما يؤدي إلى القتل: }
$$

لقد حرصت التربية الإسلامية على سد الذرائع المفضية إلى جلب المفاسد وتفويت المصالح، فحرمت

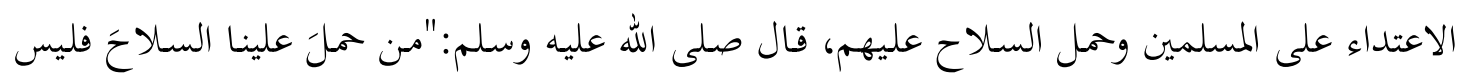

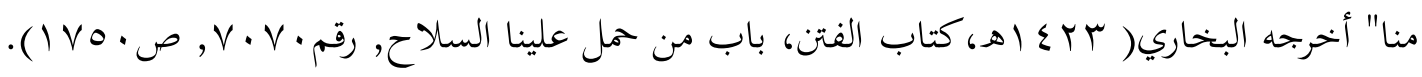
ذكر ابن حجر(V) •ـ اه,صVY) أن المراد هنا ممل السلاح على المسلمين لقتالهم به بغير حق لما فيه من تخويفهم وإدخال الرعب لقلوبكم.

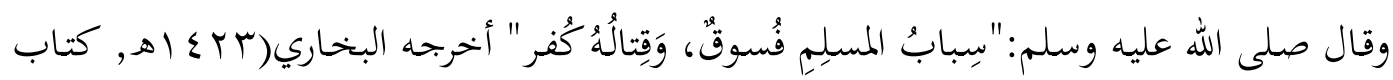

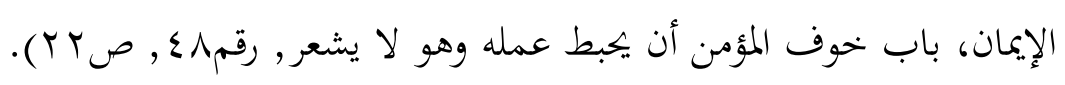

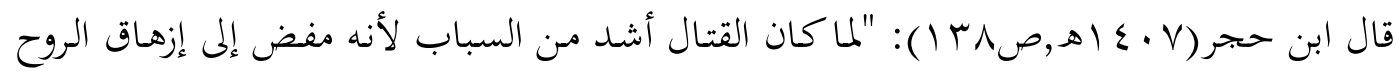

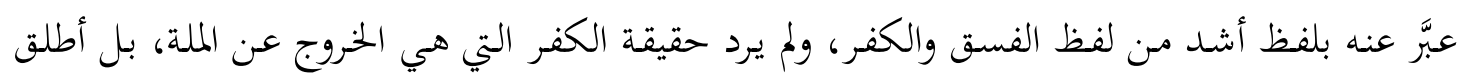
عليه الكفر مبالغة في التحذير".

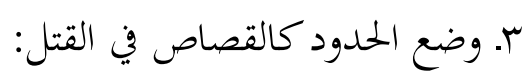
لقد شرعت التربية الإسلامية العديد من الحدود وذلك عبر الكثير من النصوص الشرعية منها قوله

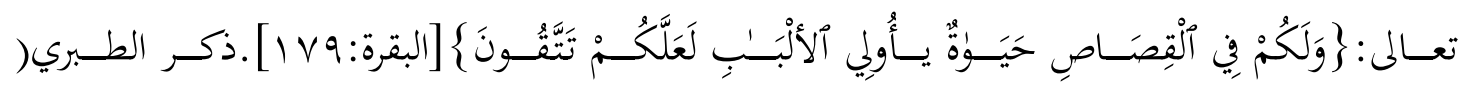

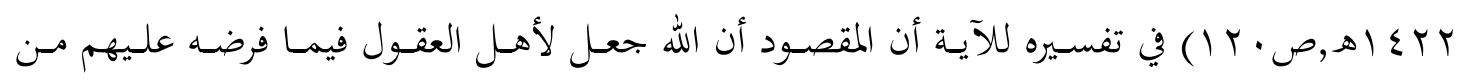

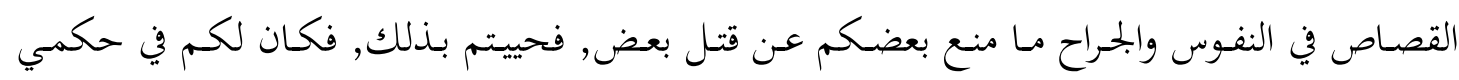
بينكم بذلك حياة. ع. التربية على فضل العفو عن القصاص:

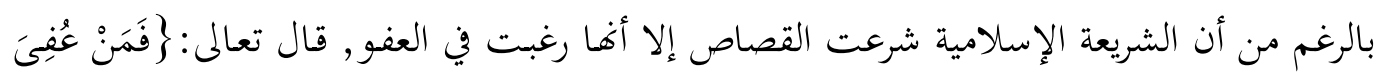

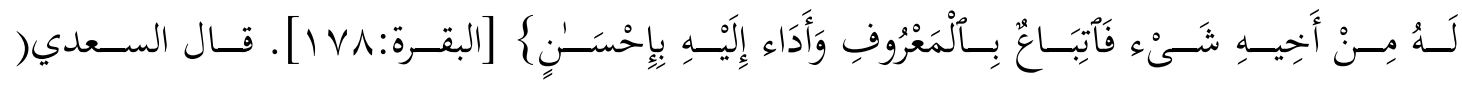




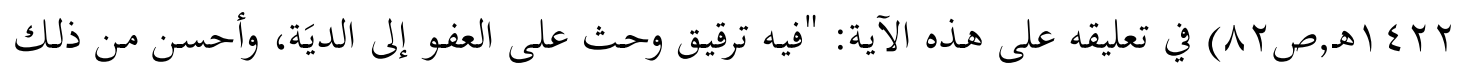
العفو بحاناً".

هـ التربية على تحريم الانتحار حفظا للنفس البشرية: فعن أبي هريرة رضي الله عنه عن النبي صلى الله عليه وسلم قال:" مَن ترَدى من جبل فقتلَ نفسَه فئه

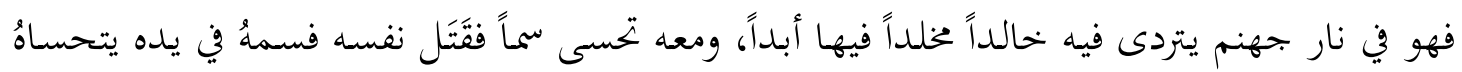

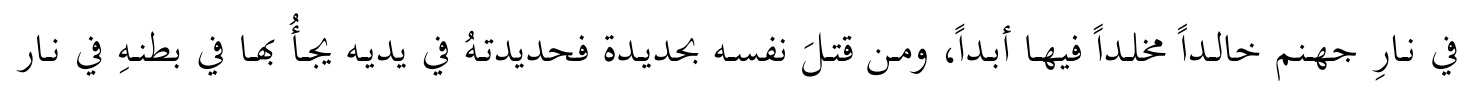

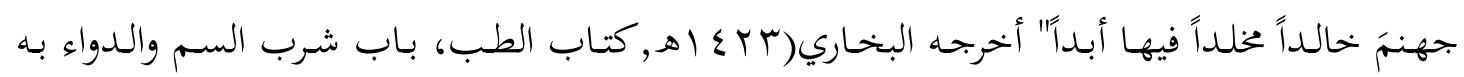

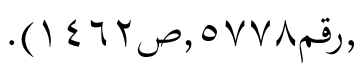

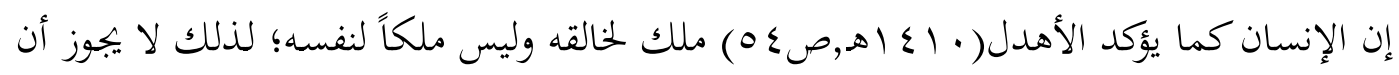

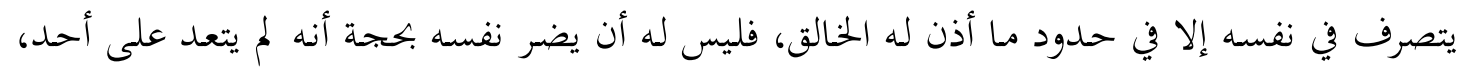
لأن اعتداءه على نفسه كاعتدائه على غيره عند الله تعالى. آ. التربية على إباحة المخظورات للضرورة:

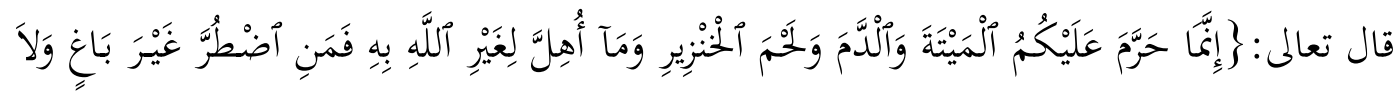

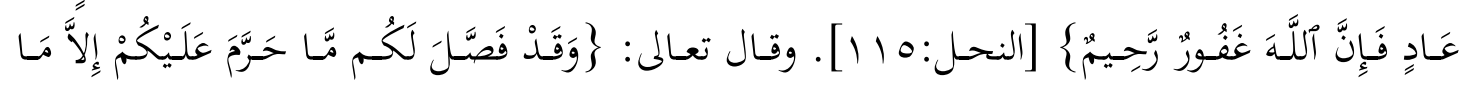

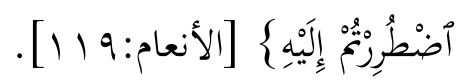

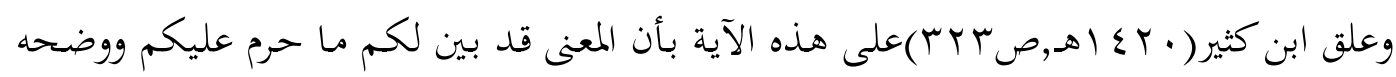

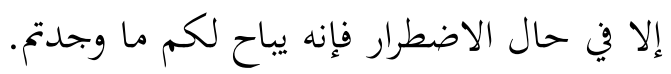

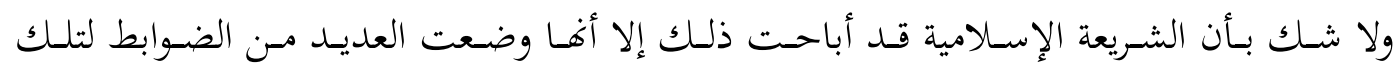

المبحث الثالث: التطبيقات التربوية المعاصرة للمقصـد الثالث من مقاصـد الثريعة وهو حفظ

بالعقل كان الإنسان إنسانا, وبه تميز عن سائر المخلوقات, وسخرت لخدمة الكائنات, فالإنسان في

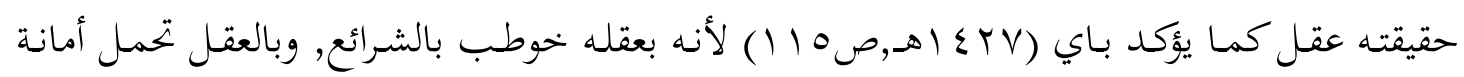
التكليف.

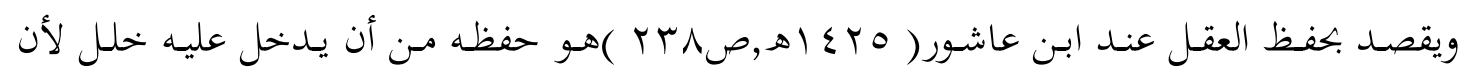

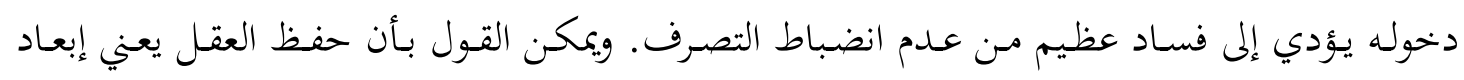


وتحريم كل مـا يفسده سواء كانت مفسـات حسية كالخمور والمخحدرات وما شابهها أم من المفسدات

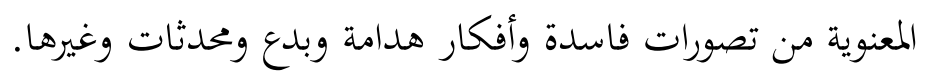
أما عن التطبيقات التربوية لمقصد حفظ العقل فيمكن إجماها على النحو الآتي:

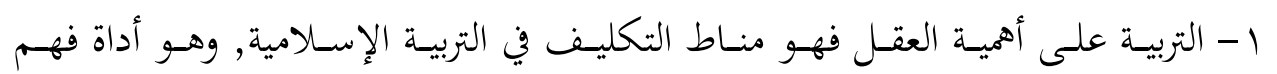

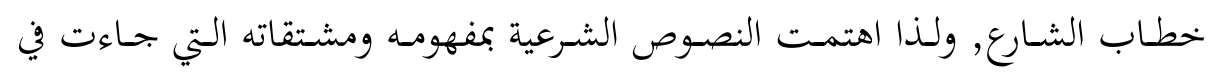

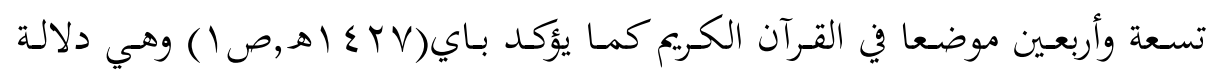

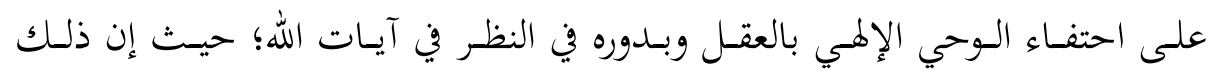

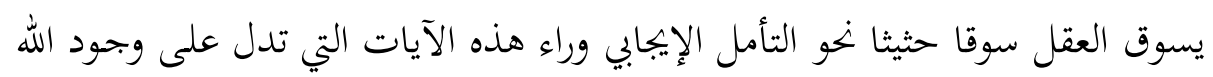

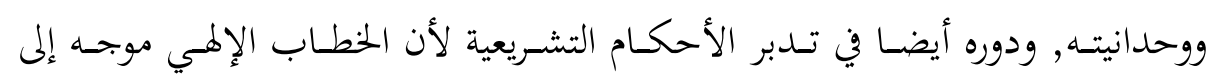

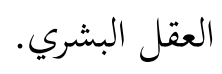

ץ- فرضية طلب العلم, فالعلم هو الخاصية الأولى في الإنسان, لذلك عرض القرآن الكريم

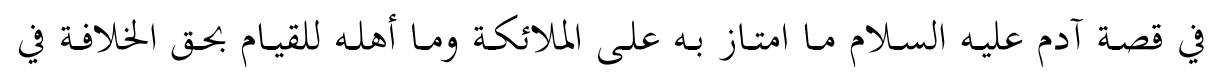

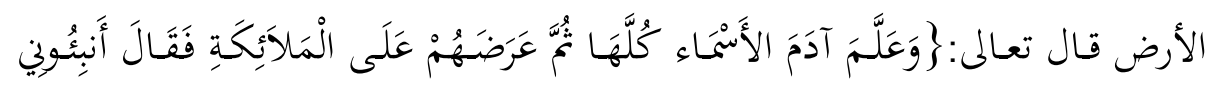

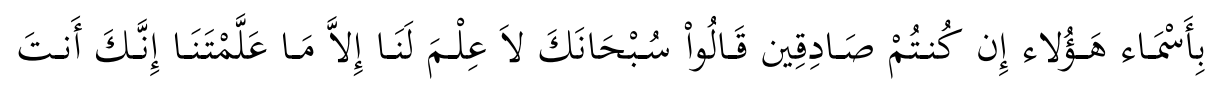

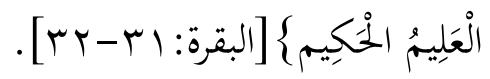

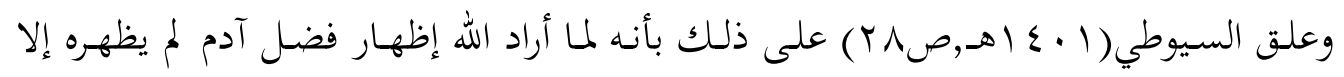

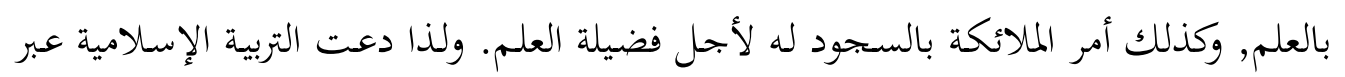

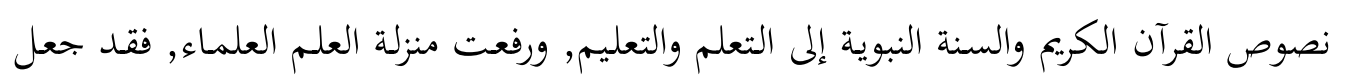

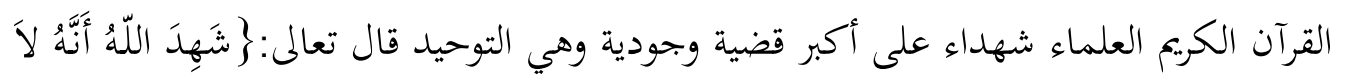

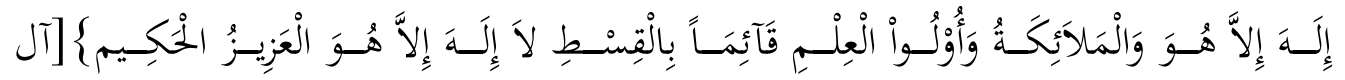
عمران:11 [1/

r- التربية على تحرير العقل من إرث التصورات والأفكار الجاهلية التي تعتقد الخرافة وبتعل

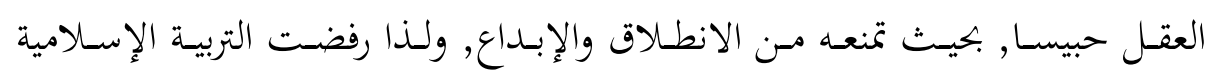

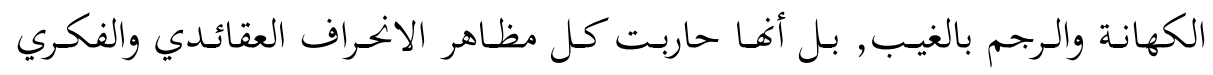

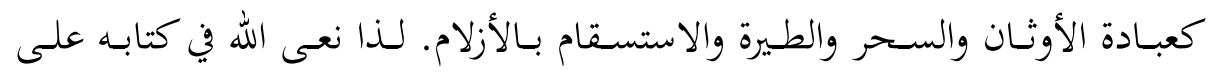

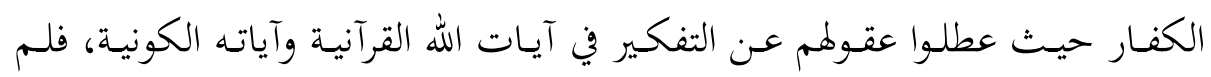

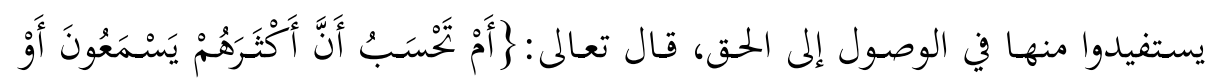

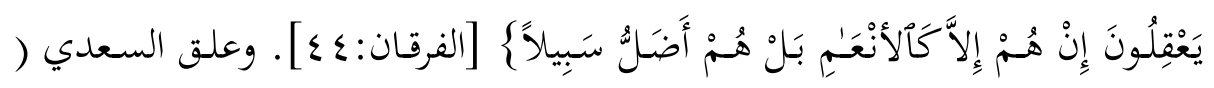

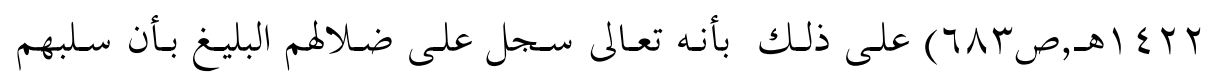


العقول والأسماع، وشبهـم في ضلالهم بالأنعام السائمة التي لا تسمع إلا دعاء ونداء،

$$
\text { صم بكم عمي فهم لا يعقلون. }
$$

ع - التربية على المحافظة على صحة العقل, فقد منعت التربية الإسلامية كل من شأنه إزالة

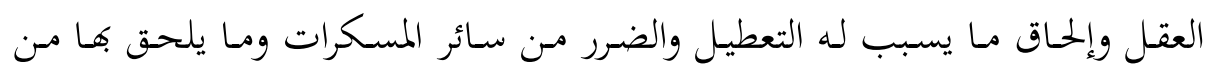

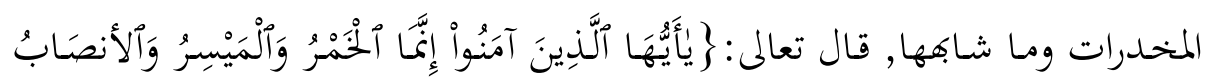

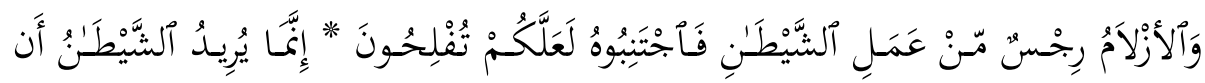

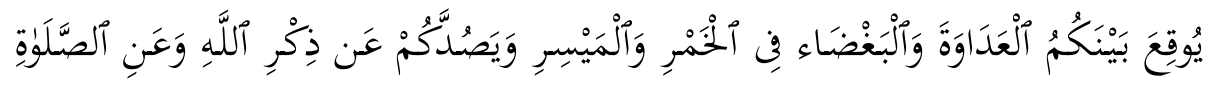

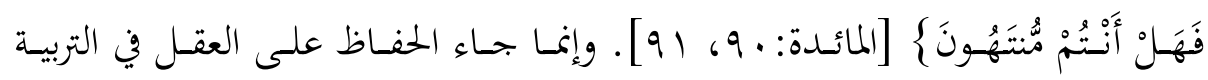

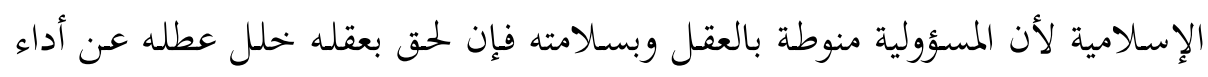
وظيفته وسقطت مسؤوليته. والعقل التام موضع الثناء؛ ولذا أثنى الرسول صلى بلى الله عليه

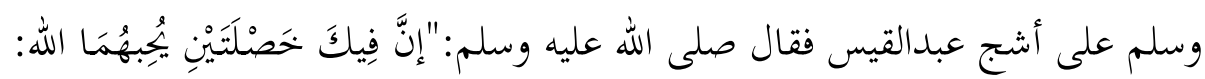

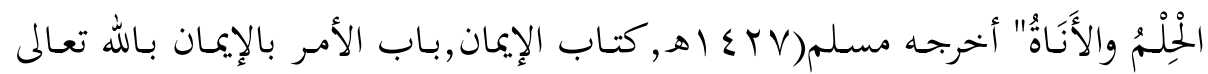

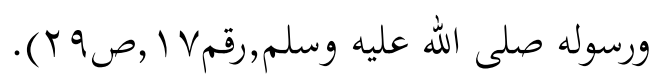

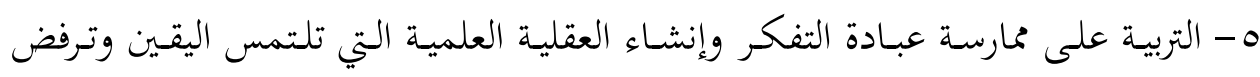

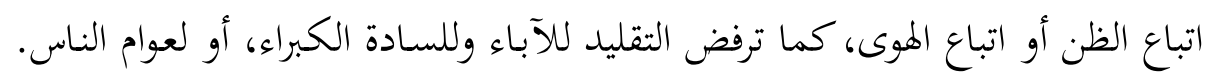

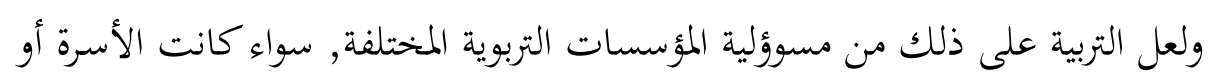
المدرسة أوالمسجد أو وسائل الإعلام وغيرها.

المبحث الرابع: التطبيقـات التربويـة المعاصـرة للمقصـد الرابع مـ مقاصـد الثـريعة وهو حفظ النسب( النسل): إن حفظ النسل من الركائز الأساسية في الحياة ومن أسباب عمارة الأرض وفيه تكمن قوة الأمم وبه تكون مرهوبة الجحانب عزيزة القدر تحمي دينها ونفوسها وتصون أعراضها وأموالها.

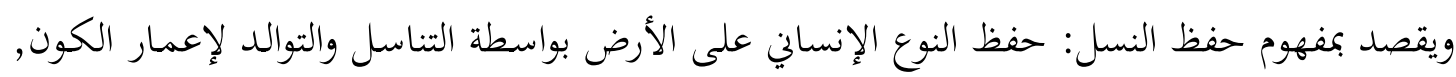

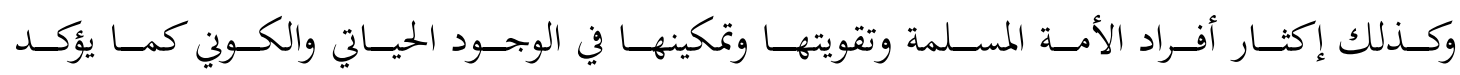

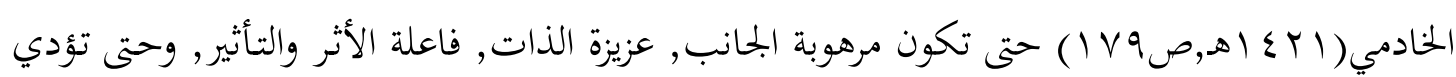
رسالة الاستخلاف في الأرض والشهادة على الناس. أما عن التطبيقات التربوية لمقصد حفظ النسل والنسب فيمكن إجمالها في الآني: 1- التربية على الترغيب في تكثير النسل: 
فقد شجعت التربية الإسلامية على تكثير النسل من ذلك ماورد عن معقل بن يسار رضي الله عنه

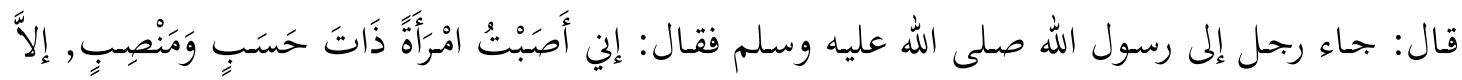

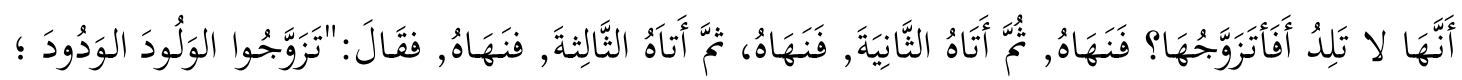

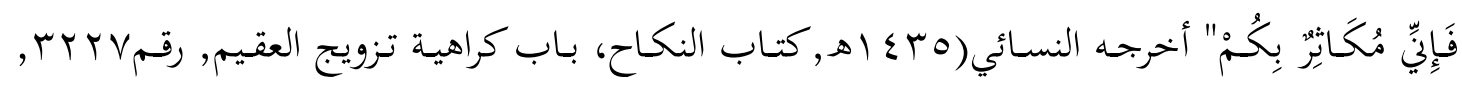

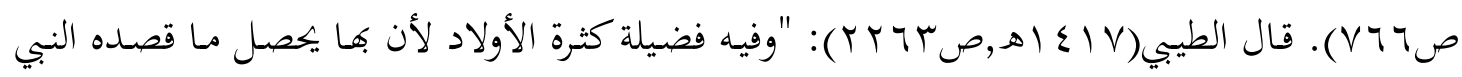
صلى الله عليه وسلم من المباهاة".

ץ- التربية على الترغيب في النكاح والتحذير من عدم الرغبة فيه:

فقد حثت التربية الإسلامية على النكاح وجعلته الطريق الحلال للتكاثر حفظا للنوع الإنساني من

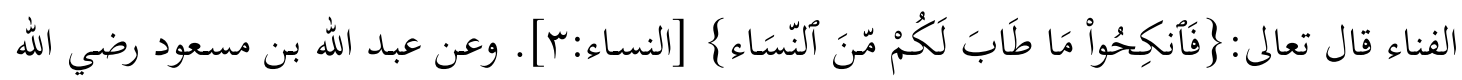

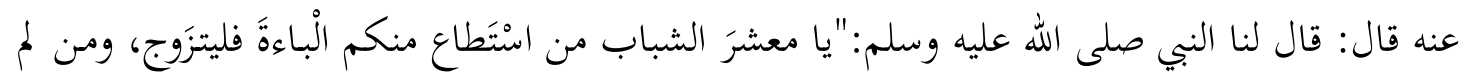

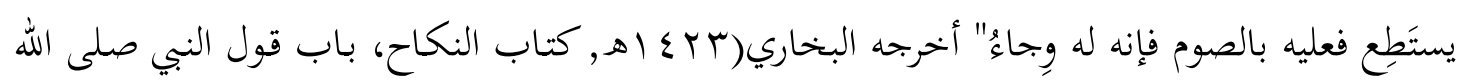

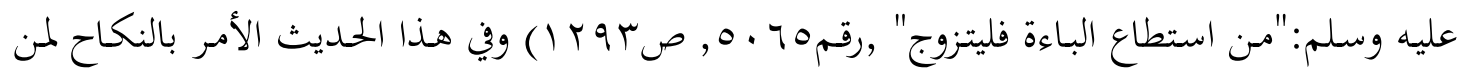
استطاعه وتاقت إليه نفسه.

r- التربية على حرمة قتل الأولاد وإجهاض الحوامل:

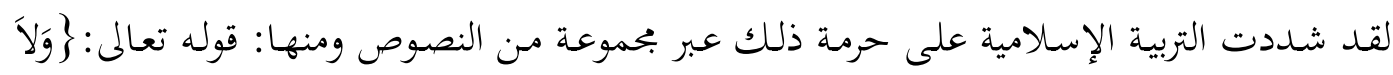

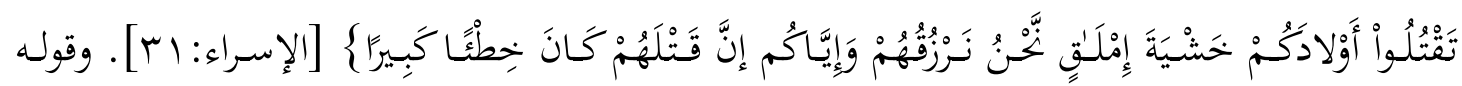

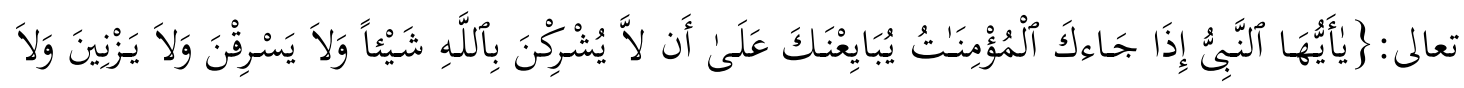

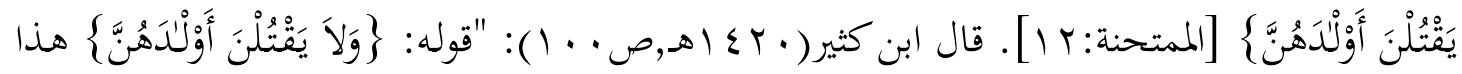

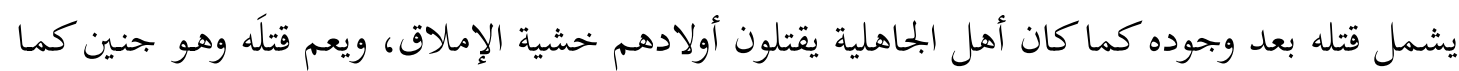
يفعله بعض الجهلة من النساء تطرح نفسها لئلا تحبل إما لغرض فاسد أو ما أشبهه". ع - التربية على حرمة نفي النسب أو إثباته على خلاف الواقع:

لقد أكدت التربية الإسلامية على هذ الأمر نظرا لما له من تأثير على انتظام حياة الأسرة والبمتمع

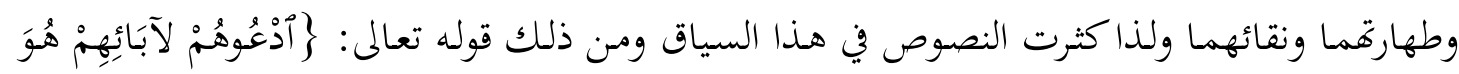

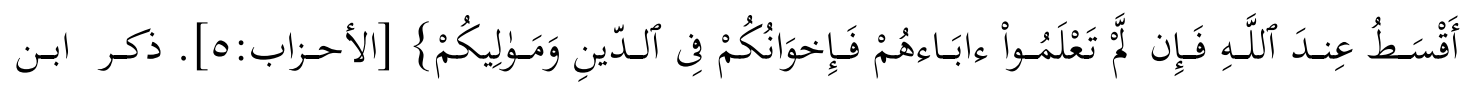




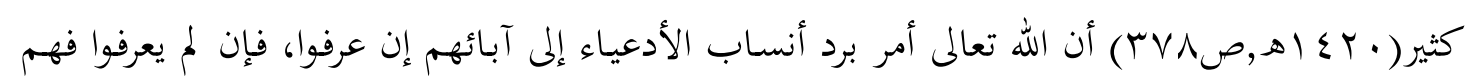

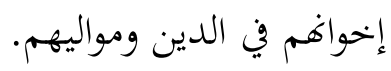

وعن واثلة بن الأسقع رضي الله عنه قال: قال رسول الله صلى الله عليه وسلم:"إن من أعظم الفِرى

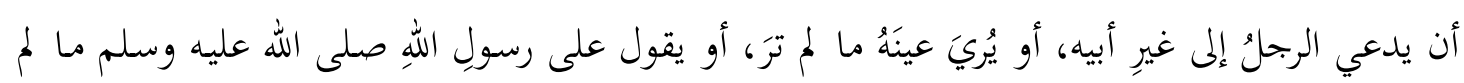

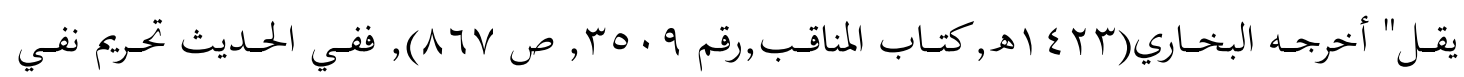
النسب المعروف والادعاء إلى غيره.

ه- التربية على حرمة الزنا واللواط والقذف:

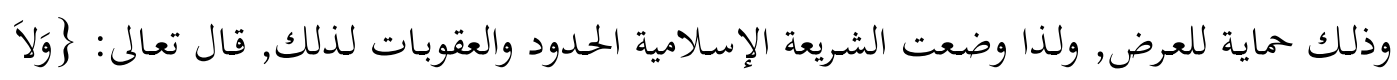

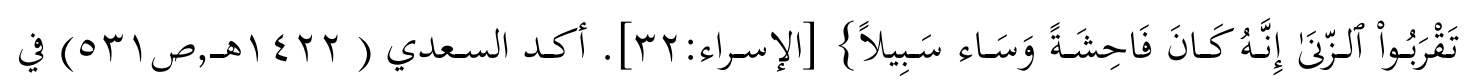

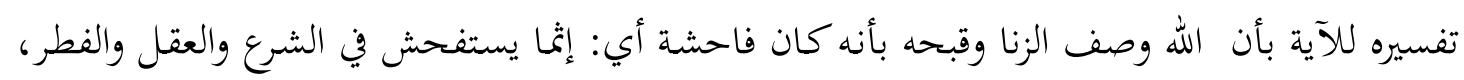

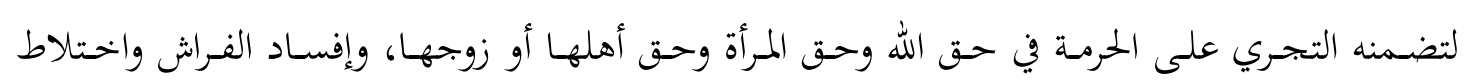

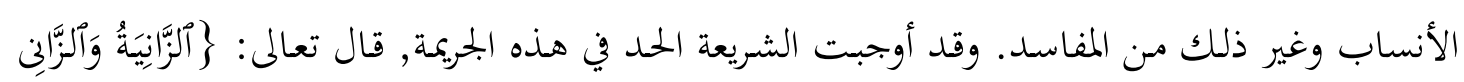

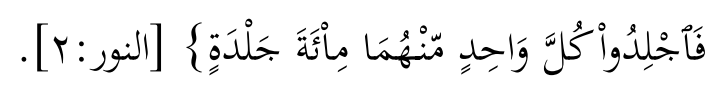
أما بالنسبة للواط فعن ابن عباس رضي الله عنهما عن النبي صلى الله عليه وسلم قال: "مَن وجَدتمُوهُ

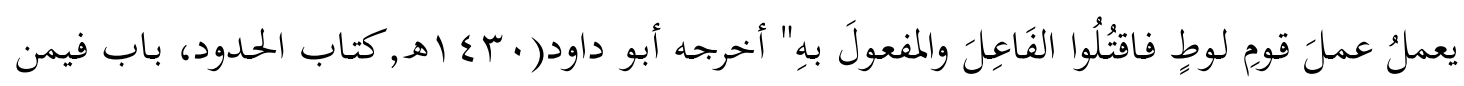

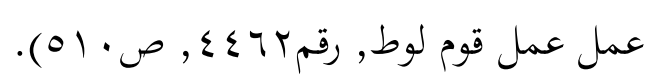

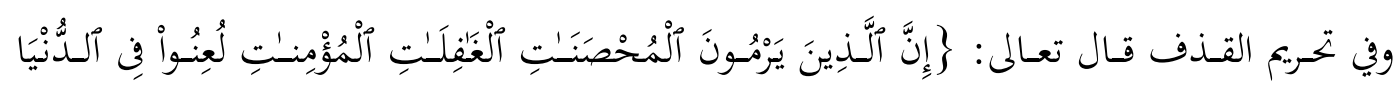

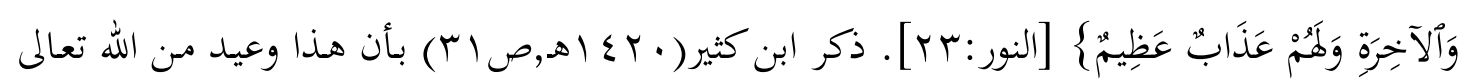
للذين يرمون المصصنات الغافلات المؤمنات. والقذف كبيرة من الكبائر المنصوص عليها, فعن أبي هريرة

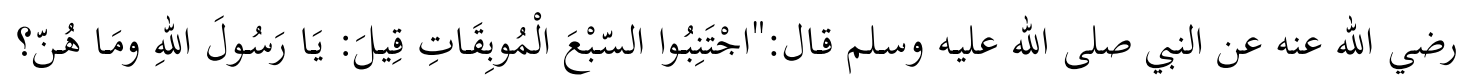

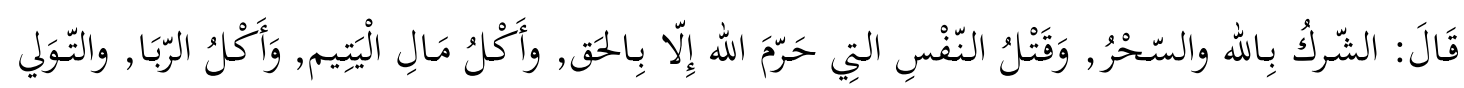

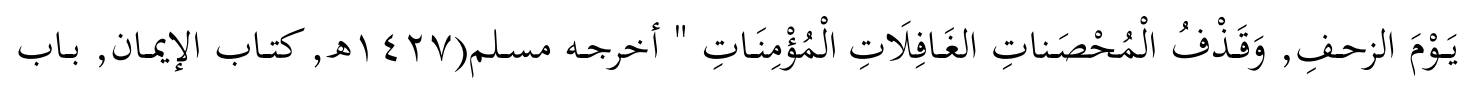

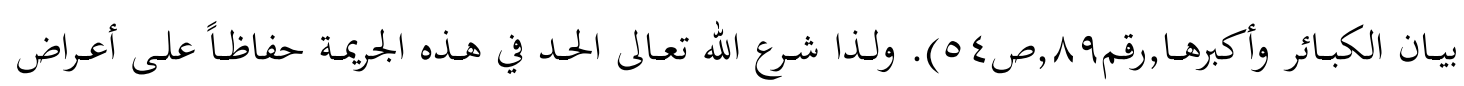
المؤمنين والمؤمنات. 
لقد منعت التربية الإسلامية الزنا وسدت منافذه وذرائعه كالملوة والتبرج ومنعت اللواط والسحاق وعاقبت الشاذين والمنحرفين حماية للعرض والشرف من الفوضى والتداخل والتلاعب.

المبحث الخامس: التطبيقات التربوية المعاصرة للمقصد الخامس من مقاصد الشريعة وهو حفظ

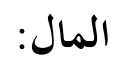
لقد ورد لفظ المال في القرآن الكريع مفردا وجمعا, معرفا ومنكرا, وهذا دليل على اهتمام الإسلام به,

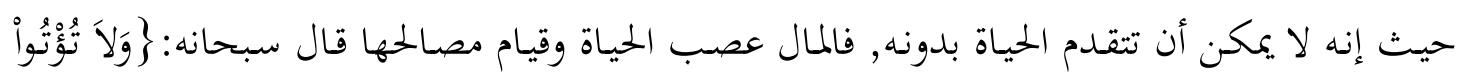

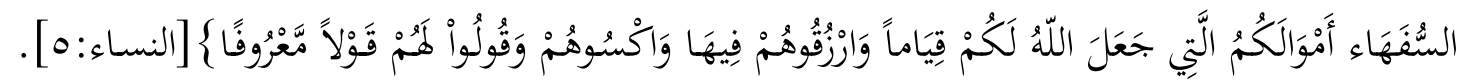

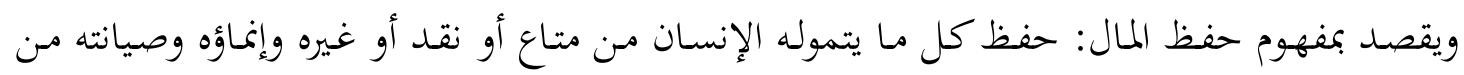

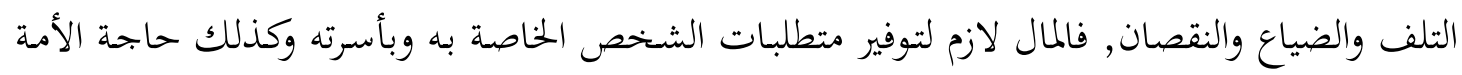

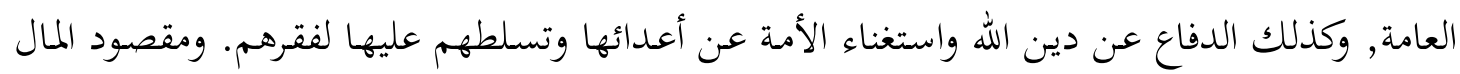
هو قيام مصالح الدين والدنيا وليس المفاخرة به وكنزه وحصول المباهاة. أما عن التطبيقات التربوية لمقصد حفظ المال فيمكن إجمالها في الآتي: 1- التربية على أن المال مال الله والناس مستخلفون فيه:

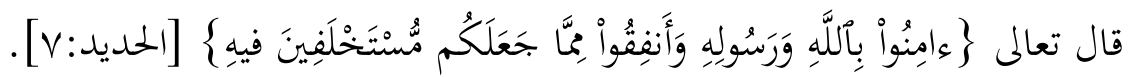

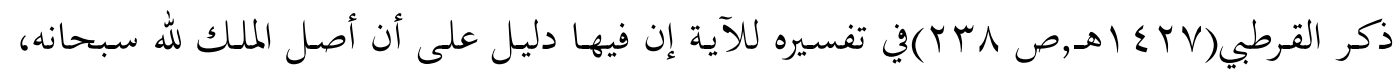
وأن العبد ليس له إلا التصرف الذي يرضي الله فيثيبه على ذلك بالجنة.

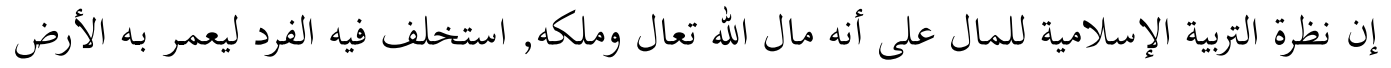

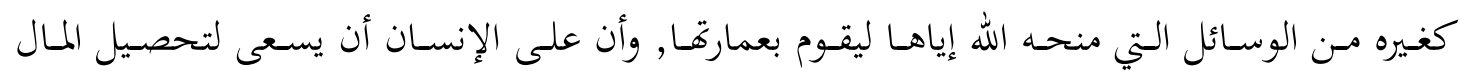

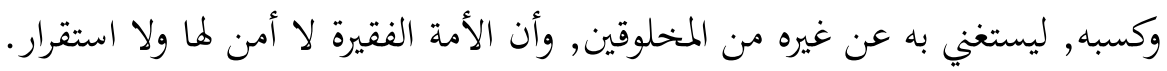
ץ- التربية على السعي المشروع في طلب المال وكسبه:

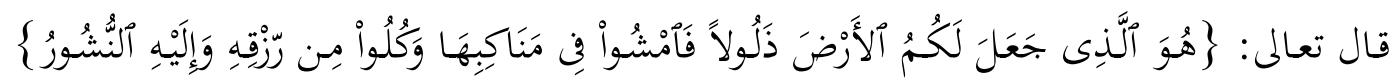

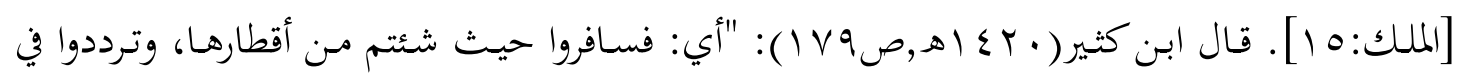

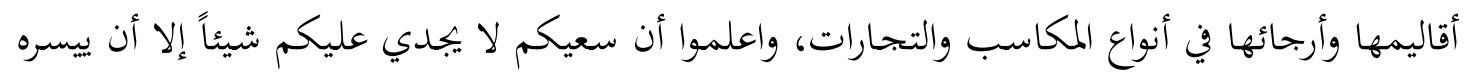

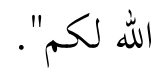

وعن الزبير بن العوام رضي الله عنه عن النبي صلى الله عليه وسلم قال:"لأَنْ يأَحُذَ أحسدم حبلَهُ

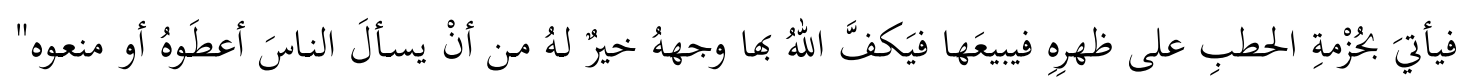

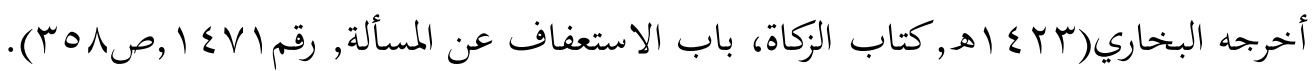


فالفرد إن ترك السعي في طلب الزرق وترتب على ذلك فقره واضطراره إلى سؤال الناس واستجدائهم

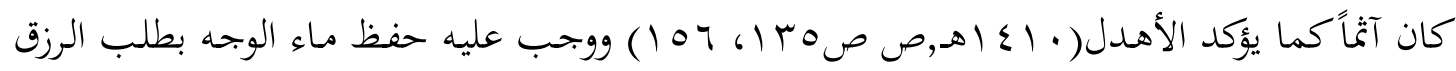

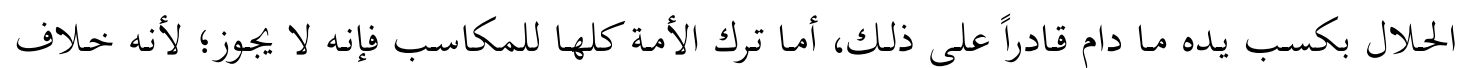

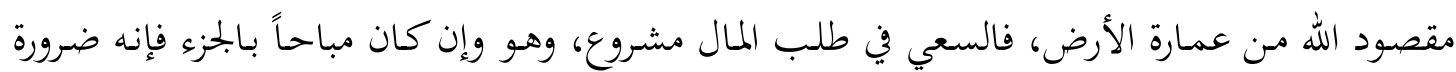

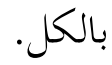

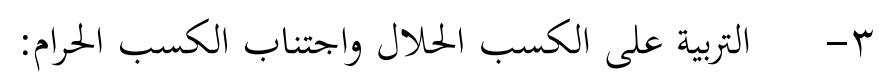

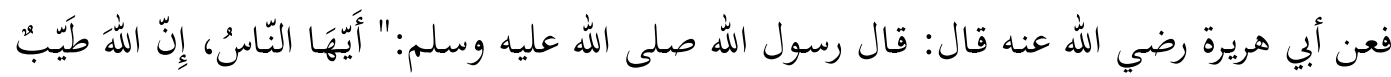

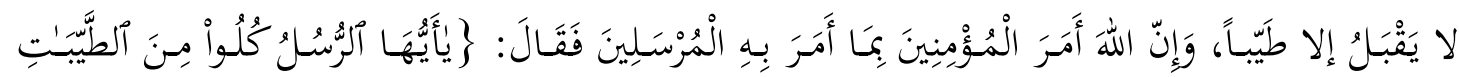

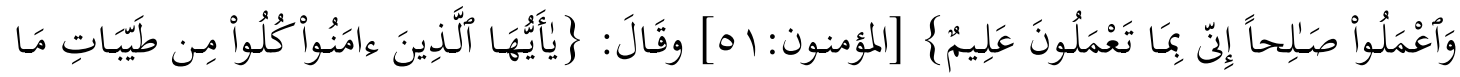

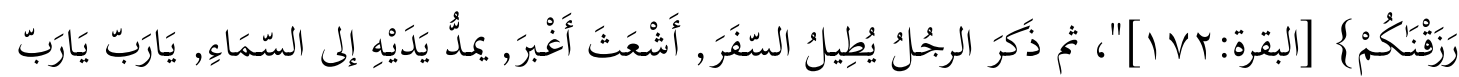

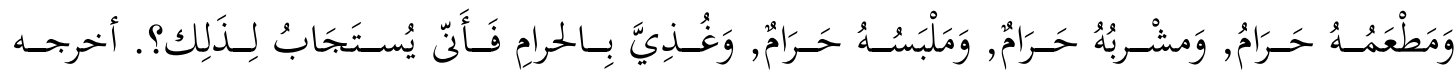

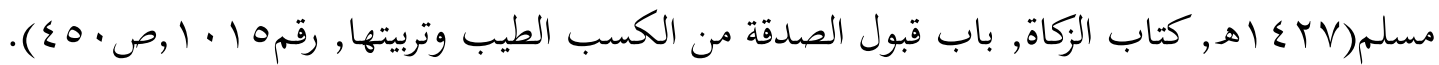
قال النووي(د-ت,صع ع ج): "فيه الحثث على الإنفاق من الحلال والنهي عن الإنفاق من غيره،

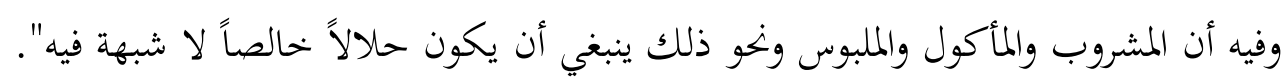
ع - - التربية على عدم إضاعة المال:

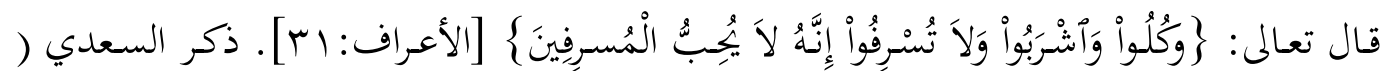

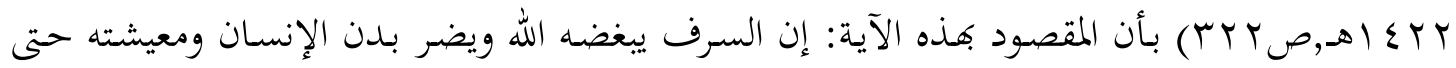
إنه ربما أدت به الحال إلى أن يعجز عما يجب عليه من النفقات. لهاتئ.

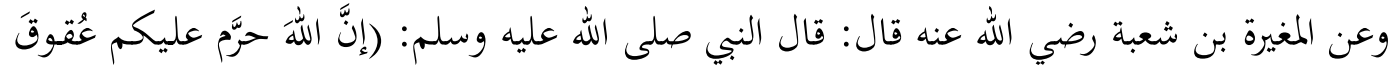

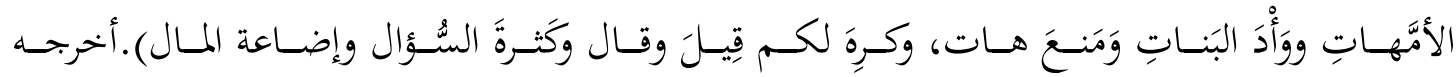

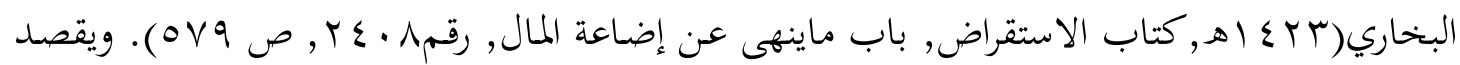

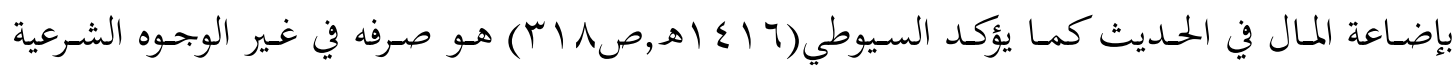

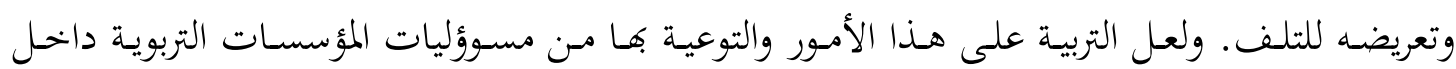

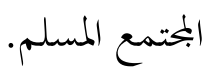

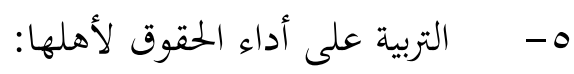

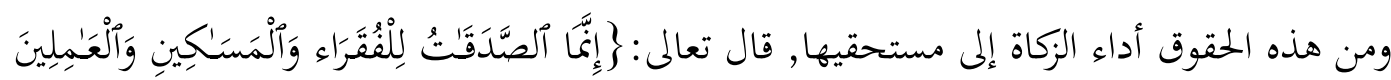

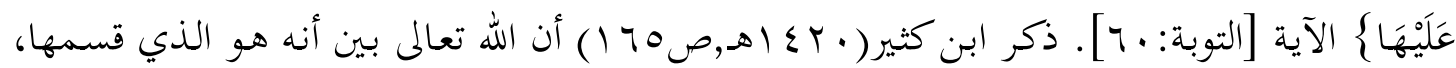


وبين حكمها، وتولى أمرها بنفسه، ولم يكل قسمها إلى أحد غيره، فجزأها لهؤلاء المذكورين. ولا شك

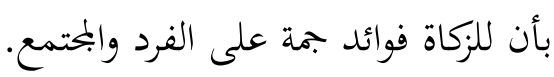
ومن الحقوق أيضا أداء الديون لأصحاهما, فعن أبي هريرة رضي الله عنه عن النبي صلى الله عليه وسلم

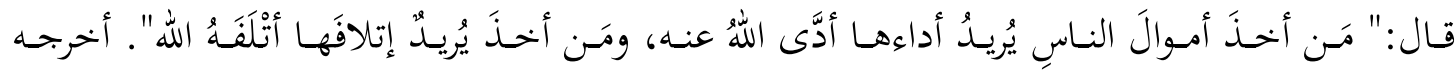

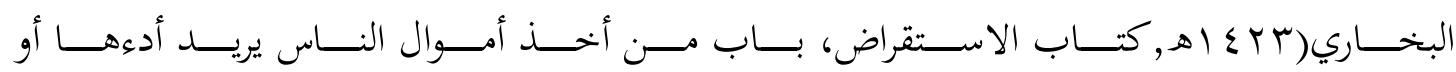

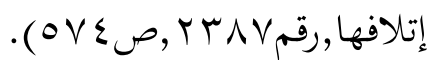

$$
\text { צ- - التربية على حماية الأموال من السفهاء: }
$$

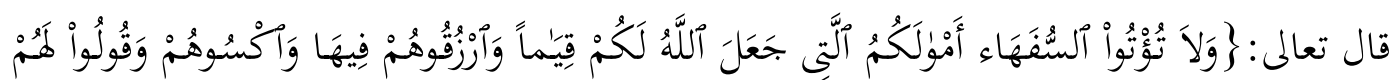

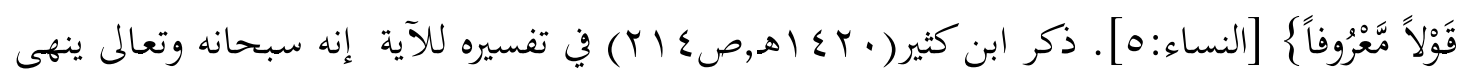

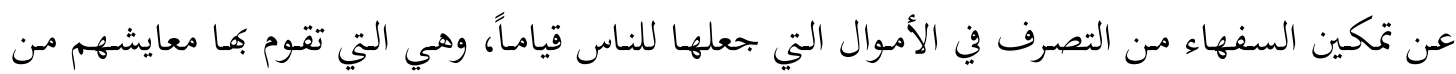

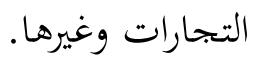

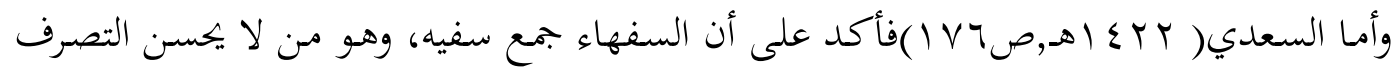

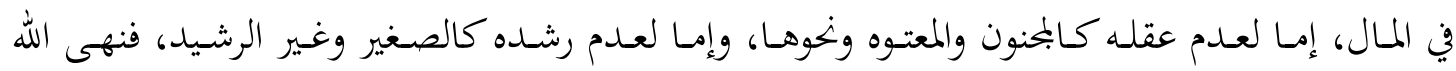

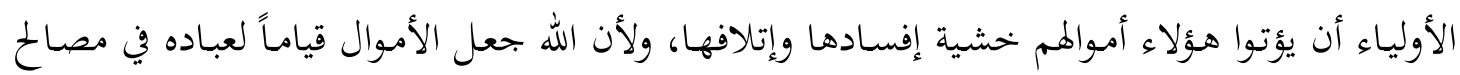

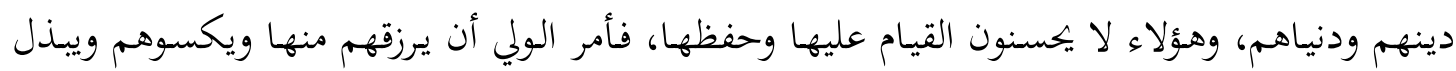

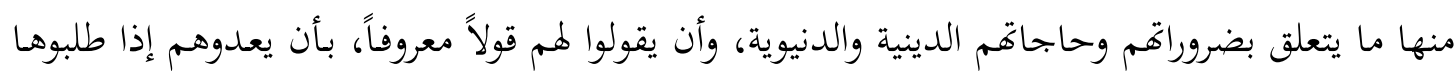
أفم سيدفعوها لهم بعد رشدهم ونخو ذلك، ويلطفوا لهم في الأقوال جبراً لخواطرهم.

V- التربية على حرمة كل صور وأوجه أكل أموال الناس بالباطل, كالتحايل والتزوير واستغلال النفوذ والسلطة والتغرير والغبن والغش والسرقة والرشوة والغصب, وتشريع العقبات والزواجر المترتبة على ذلك.

\section{النتائج والتوصيات:}

في ضوء ماسبق, توصلت الدراسة إلى العديد من النتائج وهي على النحو الآتي: 1- كثفت الدراسة الحالية بأن دراسة التطبيقات التربوية المعاصرة لمقاصد الشريعة الضرورية هو تأكيد على خلود الشريعة الإسلامية وواقعيتها وصلاحيتها للتطبيق في كل زمان ومكان

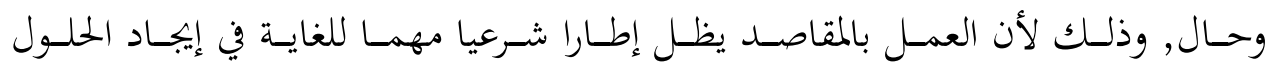

$$
\text { للمشكلات والمستجدات التربوية. }
$$


Y - - أن من التطبيقات التربوية لمقصد حفظ الدين التربية على العمل به والدعوة إليه والدفاع عنـهـ, كـذلك محاربـة المعتقــات الفاسـدة والأفكـار المنحرفـة مـع ضـرور تفعيـل دور وسـائل الإعلام المختلفة في الحفاظ على الدين, كذلك من التطبيقات تشجيع ثقافة الحوار داخل

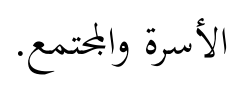

ץ- - ب أن مـن التطبيقـات التربوية لمقصد حفظ النفس التربية على حرمة الاعتداء على النفس ومنع كل مـايؤدي إلى القتل, ووضـع الحـدود مـع التربيـة على فضل العفو عن القصـاص, كذلك من التطبيقات تحريم الانتحار وإباحة المخظورات حفاظا على الأنفس.

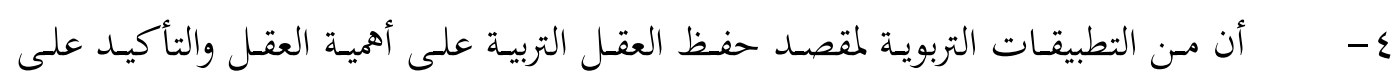

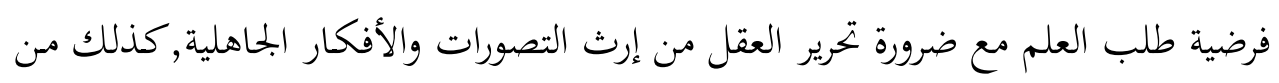
التطبيقات التربوية المحافظة على صحة العقل مع التربية على ممارسة عبادة التفكر لإنشاء العقلية العلمية التي ترفض اتباع الظن والهوى.

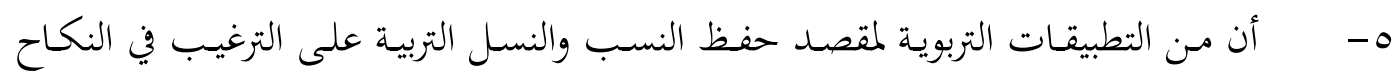
وتكثير النسل مع التأكيد على حرمة قتل الأولاد ونفي النسب وكذلك حرمة الزنا واللواط والقذف.

؟- أن من التطبيقات التربوية لمقصد حفظ المال التربية على أن المال مال الله مع ضرورة السعي

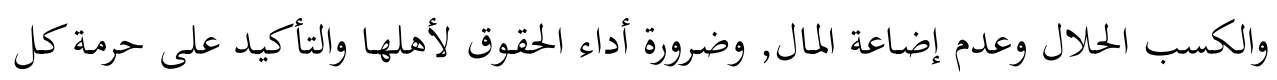
صور أكل أموال الناس بالباطل. وفي ضوء ماسبق من نتائج فإن الباحثة توصي بالآتي:

ا - الاهتمام بتفعيل التطبيقات التربوية لمقاصد الشريعة الضرورية في مؤسسات البمتمع التربوية. ץ- إدراج مقرر دراسي يتعلق بمقاصد الشريعة الإسلامية في الخطط الدراسية لبرامج الماجستير والدكتوراة في تخصص التربية الإسلامية في جامعات البلدان الإسلامية.

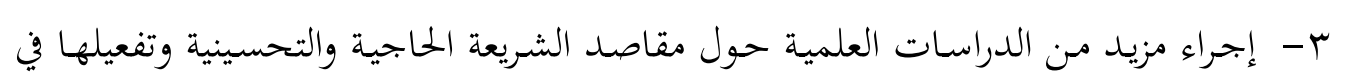
البحال التربوي.

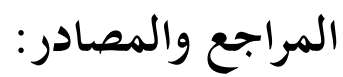
أسعد المحاسن, لحرش(r ا • r م).ترتيب المقاصد الضرورية بين المتقدمين والمعاصرين وأهميتها للمفتي. بحلة المسلم المعاصر, $\cdot(1 \leq 7-1 \leqslant 0)$ الأهدل,عبد الله • إـ اهـ).الإسلام وضرورات الحياة. السعودية:دار المختمع. 
باي,محمود(Y \& (هـ).مقصد حفظ العقل عند الإمام محمد الطاهر بن عاشور. مذكرة مقدمة لنيل درجة الماجستير في

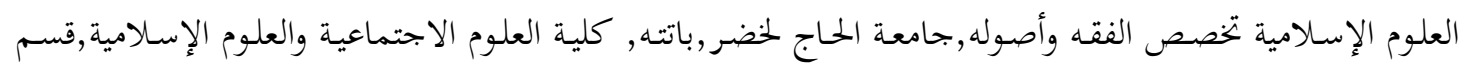
الشريعة, الجزائر.

بابكر, علي(0 1 \& اهـ ,7 19 - 19 ربيع الأول).علاقة علوم الشريعة بالعلوم الاجتماعية والانسانية المعاصرة, ورقة عمل

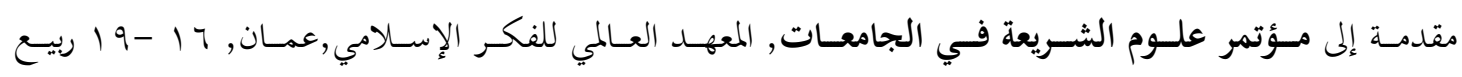
الأول,0 1ـ اهـ.

البخاري,محمد(بr \& اهـ).صحيح البخاري. بيروت -دمشق: دار ابن كثير. ابن حجر ,أحمد(V • ( اه). فتح الباري بشرح صحيح البخاري. القاهرة:دار الريان للتراث. الخنادمي, نور الدين( آY (1ه).علم المقاصد الشرعية. الرياض:مكتبة العبيكان. الخادمي, نور الدين(YV \& اهـ).المقاصد الشرعية: ضوابطها,تاريخها.تطبيقاتها.الرياض:دار كنوز إشبيليا للنشر والتوزيع. الريسوني, أحمد(آبـ اهـ).مدخل إلى مقاصد الشريعة. القاهرة:دار السلام. زقزوق ,محمود(ع ؟ \& اهـ).مقاصد الشريعة الإسلامية وضرورات التجديد. مصر: وزارة الأوقاف. السجستاني, سليمان(· r ع اهـ).سنن أبي داود.تحقيق: شعيب الارنؤوط ومحمد كامل, سوريا:دار الرسالة العالمية.

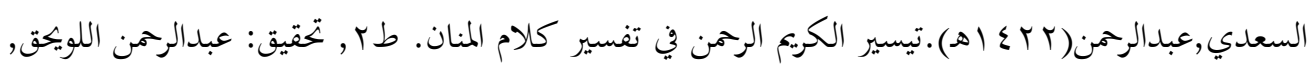
الرياض:دار السلام للنشر التوزبع. السيوطي,عبدالرمن( ( ـ اهـ). الإكليل في استنباط التنزيل. تحقيق:سيف الدين الكاتب, بيروت: دار الكتب العلمية. السيوطي, عبدالرمن(7 أ أ (ه). الديباج على صحيح مسلم بن الحجاج. تحقيق: ابو إسحاق الحويني, الخبر:دار ابن عفان للنشر والتوزيع.

الشاطبي,إبراهيم (د-ت).الموافقات في أصول الشريعة. تحقيق: عبد الله دراز وعبد السلام عبد الشافي, الرياض: وزارة الأوقاف السعودية. الطبري,محمد(Y I I ().تفسير الطبري جامع البيان عن تأويل آي القرآن. تحقيق: عبد الله التركي, القاهرة: هجر للطباعة والنشر والتوزيع والإعلان.

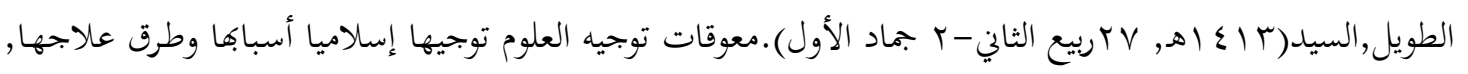
ورقة عمل مقدمة إلى مؤتمر التوجيه الإسلامي للعلوم, مركز صالح كامل للاقتصاد الإسلامي بجامعة الأزهر ,القاهرة,

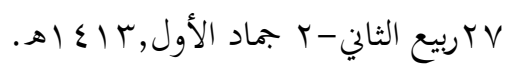
الطيب, الحسين( V V ا اهـ).شرح الطيبي على مشكاة المصابيح. تحقيق: عبدالحميد هنداوي, مكة المكرمة: مكتبة نزار الباز. 
الظبي,منور( • ( • ץ). التطبيقـات التربوية لمقصد حفظ العقل في الإسلام بمحتوى منـاهج التربية الإسـلامية للمرحلة المتوسطة رسالة ماجستير غير منشورة,جامعة طيبة, كلية التربية,قسم المناهج وطرق التدريس, المدينة المنورة.

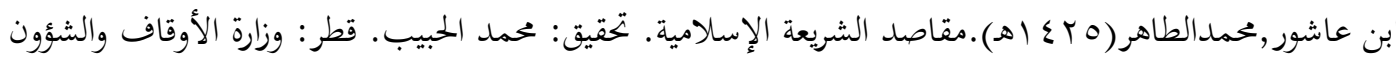
الإسلامية. عبدالباقي, محمد,فؤاد(r \& (هـ).المعجم المفهرس لألفاظ القرآن الكريم. القاهرة:دار الحديث. العلواني, طه(ب إـ اهـ).إصلاح الفكر الإسلامي بين القدرات والعقبات.ط ب, الرياض- هيرندن: الدار العالمية للكتاب الإسلامي والمعهد العالمي للفكر الإسلامي. عمر ,أحمد (^ . . rم).معجم اللغة العربية المعاصرة. القاهرة:عالم الكتب. فنسنك.أ.ب (7 بهو (م).المعجم المفهرس لألفاظ الحديث النبوي. تحقيق: محمد فؤاد عبدالباقي, ليدن :مكتبة بريل.

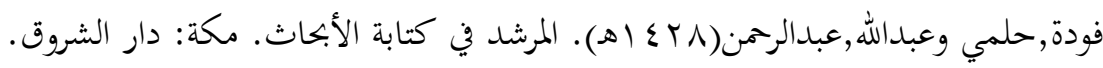
القاضي,محمد(r . . r م).دور الأسرة المسلمة في تربية أولادها على حفظ الضروريات من مقاصد الشريعة. رسالة ماجستير غير منشورة, جامعة أم القرى, كلية التربية, مكة المكرمة. القرطبي,محمد(Y \& ا هـ). الجامع لأحكام القرآن. تحقيق: عبد الله التركي, بيروت: مؤسسة الرسالة.

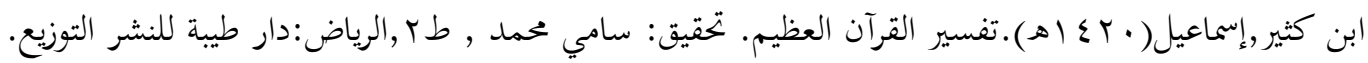
مختار ,كمال المبارك(7 . 다).القيم التربوية في مقاصد الشريعة دراسة في مقرر الفقه للصفين السابع والثامن مرحلة الأساس. رسالة ماجستير غير منشورة, جامعة أم درمان الإسلامية ,كلية التربية,السودان. ابن منظور ,محمد( آ⿱ اهـ).لسان العرب. السعودية: وزار الشؤون الإسلامية والأوقاف والدعوة والإرشاد. الميلاد,زكي (د-ت).الفكر الإسلامي بين التأصيل والتجديد ـبيروت: دار الصفوة. النيسابوري,مسلم(YV \& (ه).صحيح مسلم. تحقيق: نظر الفاريابي, الرياض:دار طيبة للنشر التوزيع. النسائي, أحمد(0بـ اهـ).سنن النسائي المجتبز بيروت: مؤسسة الرسالة. النووي,يهيى(د-ت).المنهاج في شرح صحيح مسلم بن الحجاج. الأردن: بيت الأفكار الدولية. يالجن, مقداد(9 1ـ 1هـ).مناهج البحث وتطبيقاتا في التربية الإسلامية. الرياض:دار عالم الكتب. 
اليوبي,محمد(1 إ اهـ).مقاصد الشريعة الإسلامية وعلاقتها بالأدلة الشرعية. الخبر:دار الهجرة للنشر والتوزيع.

\section{:Abstract}

